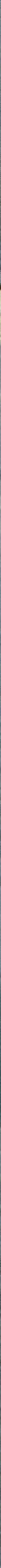


Front cover photograph by F. Carsey: Surface-based microwave emissivity measurements in the eastern Beaufort Sea, July 1982.

Back cover photograph by A. Hielscher: The research vessel Polar Bjørn in the marginal ice zone of the Greenland Sea, July 1983.

This report was produced by the University of Washington Applied Physics Laboratory and Department of Printing. Copies are available at no cost from

Oceanic Processes Branch, Code EE

NASA Headquarters

Washington, DC 20546

or from

Applied Physics Laboratory

University of Washington

Seattle, WA 98105 


\section{Passive Microwave Remote Sensing for Sea Ice Research}

Report of the NASA Science Working Group for the Special Sensor Microwave Imager (SSM/I) 
Members of the NASA Science Working Group

for the Special_Sensor_Microwave Imager -

Norbert Untersteiner, Chairman

Polar Science Center, Applied Physics Laboratory, University of

Washington

Roger Barry

CIRES, University of Colorado

Frank Carsey

Jet Propulsion Laboratory, California Institute of Technology

Donald Cavalieri

NASA Goddard Space Flight Center

James Cornelius

Fleet Numerical Oceanography Center

Fred Deily

Exxon Production Research Company

Douglas Eckert

Oceanographic Services, Inc.

Thomas Grenfell

Department of Atmospheric Sciences, University of Washington

Ray Godin

Naval Polar Oceanographic Center

James Hollinger

Naval Research Laboratory

David Honhart

Office of the Oceanographer of the Navy

Paul McClain

NOAA-NESS

Rene Ramseier

Atmospheric Environment Service Canada

Alan Thorndike

Physics Department, University of Puget Sound

Patrick Welsh

NORDA

Thomas Wilheit

NASA Goddard Space Flight Center

Jay Zwally

NASA Goddard Space Flight Center

Additional help in preparing this report was provided by Claire Parkinson and Josefino Comiso, both at NASA Goddard Space Flight Center, and Peter Wadhams of Scott Polar Research Institute.

\section{Preceding Page Blank}

-iii- 


\section{Foreword}

During the next decade, satellites carrying a range of sensors in nearpolar orbit will provide a unique opportunity for polar research. Our experience with Seasat and Nimbus satellites indicates that many important ice parameters can be measured using microwave radiometers to acquire global, synoptic data at coarse spatial resolution, synthetic aperture radars (SAR's) to spotlight local areas where high spatial resolution is needed, and radar altimeters to measure ice-sheet topography. To ensure that these data sources are fully exploited for polar research, NASA has formed three Science Working Groups (SWG's): a "DMSP-SSM/I Sea Ice SWG" to cover passivemicrowave data, an SWG to evaluate science applications of ERS-1 SAR data in the Alaska region, and an "Ice Sheet SWG" to assess the research potential of satellite data over the ice sheets of Greenland and Antarctica.

The report of the ERS-1 group was published in December 1983 by the Jet Propulsion Laboratory under the title "Science Program for an Imaging Radar Receiving Station in Alaska." The report of the Ice Sheet SWG will be published later in 1985. The document presented here is the report of the DMSP-SSM/I Sea Ice SWG. Together, the three reports will be used to guide NASA's research program in the polar regions, and we hope they will lead the way to cooperative programs both with other U.S. agencies and with other countries.

The DMSP-SSM/I Sea Ice SWG was established in December 1982 under the chairmanship of Norbert Untersteiner. It was charged with answering these questions:

- What problems of sea ice research could most appropriately be addressed utilizing DMSP-SSM/I data?

- What are the associated DMSP-SSM/T data requirements to help solve these problems?

In addition to fulfilling this charge, the report provides the reader with background information necessary to understand the rationale for sea ice research and to appreciate how dependent such research is on remote sensing. Moreover, the SWG activities have focused attention on the need for cooperative research aimed at improving and validating algorithms for converting satellite passive microwave data to sea ice parameters. As a consequence, this research is progressing well: analytical tools have been developed for application. to SSM/I data once they become available, and 
efforts are under way to develop new techniques for validating the remotely - sensed data: Finally, the SWG-has provided clear guidance to NASA toward development of an SSM/I data processing system to meet sea ice research requirements.

Robert H. Thomas

Manager, Polar Oceans Program

National Aeronautics and Space Administration 


\begin{abstract}
This report summarizes how data gathered by remote sensors on satellites can be utilized for sea ice research, and describes how the brightness temperatures measured by a passive microwave imager can be converted to maps of total sea ice concentration, and to the areal fractions covered by first year and multiyear ice. Several ancillary, observations, especially by means of automatic data buoys and submarines equipped with upwardlooking sonars, are needed to improve the validation and interpretation of satellite data. The design and performance characteristics of the Navy's Special Sensor Microwave Imager, expected to be in orbit in late 1985, are described. It is recommended that data from that instrument be processed to a form suitable for research applications and archived in a readily accessible form. The report concludes with a description of the sea ice data products required for research purposes and recommendations for their archival and distribution to the scientific community.
\end{abstract}




\section{Contents}

EXECUTIVE SUMMARY …..............................................................

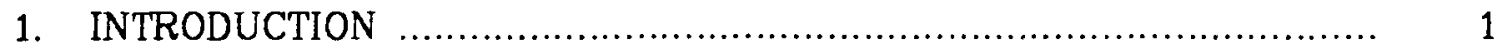

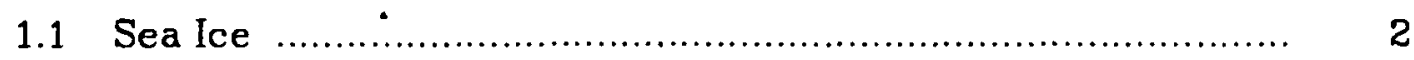

1.2 Sea Ice Research ….................................................... 4

1.3 Observations ................................................................. 7

2. SATELLITE REMOTE SENSING OF SEA ICE ................................. 9

2.1 Visible and Infrared Sensors …........................................ 9

2.2 Microwave Measurements .................................................. 10

3. METHODS OF PASSIVE MICROWAVE REMOTE SENSING …................ 18

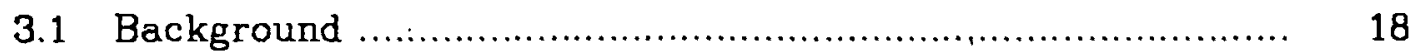

3.2 Derivation of Sea Ice Characteristics ................................. 20

3.2.1 Single frequency methods ..................................... 21

3.2.2 Multifrequency methods .......................................... 23

3.3 Observations in the Marginal Ice Zone (MIZ) ….................... 27

3.4 Multispectral Cluster Analysis ........................................ 28

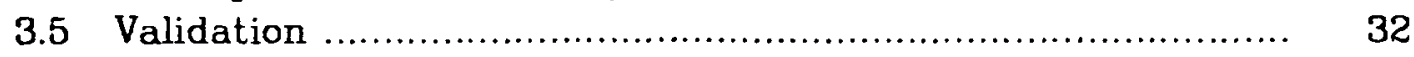

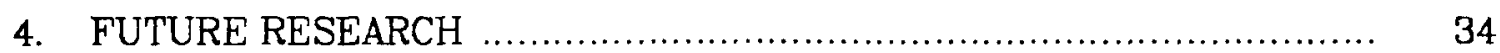

4.1 Algorithm Improvement and Validation ............................. 34

4.2 Ancillary Measurements ............................................... 35

4.2.1 Data buoys ......................................................... 35

4.2.2 Submarine data ................................................... 37

4.2.3 Other satellite measurements ................................ 39

5. THE SPECIAL SENSOR MICROWAVE IMAGER (SSM/I) ..................... 40

5.1 Description of the Instrument ........................................ 40

5.2 Data Products ............................................................ 44

5.3 Radiometer Performance Checks .................................... 45

5.4 Earth Location .............................................................. 46

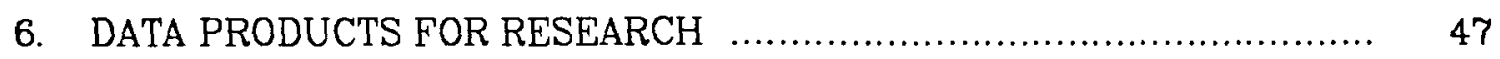

6.1 Data Archives and Access ................................................. 47

6.2 Algorithm Selection ..................................................... 49

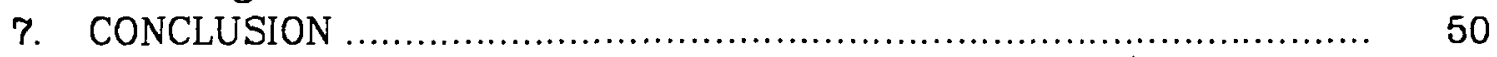

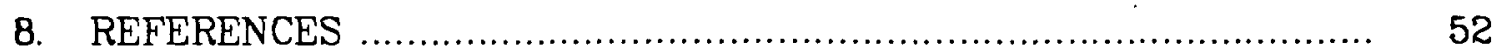




\section{List of Figures}

Figure 1. Ice and water exchange between the Arctic and Atlantic oceans viewed as an estuary exchange between two rotating tanks filled with water of different salinity.

Figure 2a. Ice drift velocity in the Arctic Basin, averaged and interpolated over all available data since the drift of Nansen's Fram (1893-1896), including data from the Arctic Data Buoy Program initiated in 1979

Figure 2b. Given the mean velocity field shown in Figure 2a, it is possible to calculate the "life expectancy" of a piece of ice in the Arctic Basin ...

Figure 3. Nimbus-? SMMR brightness temperature images of the north polar region as observed during February 3-7, 1979, at $18 \mathrm{GHz}(1.7 \mathrm{~cm})$ and $37 \mathrm{GHz}(0.81 \mathrm{~cm})$ for both horizontal and vertical polarizations.

Figure 4. Polar images of arctic sea ice concentration (a) and multiyear ice fraction (b) derived from Nimbus-7 SMMR data for the period February 3-7, 1979.

Figure 5. Southern Ocean ice concentration in percent derived from the single-frequency radiometer on Nimbus-5. 13

Figure 6. Formation of the Weddell polynya; satellite observations and results of a computer model driven by mean climate data

Figure 7. A 10-year time series of antarctic sea ice extent

Figure 8. Nimbus-7 SMMR horizontally and vertically polarized brightness temperatures at the 0.81 and $1.7 \mathrm{~cm}$ wavelengths over the annual cycle $1978 / 79$.

Figure 9. Arctic ice concentration at summer's end averaged over 1973-1976

Figure 10. The inferred cloudy sky surface albedo for the period of maximum meltpond coverage (mid-July) in 1974 .

Figure 11. Microwave brightness temperatures of sea ice and icefree (open) ocean as measured by each of the 10 Nimbus7 SMMR channels in three regions of the Arctic during February 3-7, 1979.

Figure 12. Polar images of (a) the $1.7 \mathrm{~cm}$ wavelength polarization $(P R)$ and (b) the spectral gradient ratio $(G R)$, both computed from Nimbus-7 SMMR data for February 3-7, 1979 
Figure 13a. Plot of the difference versus the sum of the horizontally and vertically polarized _Nimbus-7 SMMR_brightness - tem-peratures at the $0.81 \mathrm{~cm}$ wavelength for the entire Bering Sea region.

Figure 13b. Bering Sea ice concentration contours derived from the $0.81 \mathrm{~cm}$ wavelength channels of the Nimbus-7 SMMR data for February 19, 1983.

Figure 14. Regional variation of emissivity. Nimbus SMMR and infrared radiometer data are used to generate a scatter plot of emissivities at $37 \mathrm{GHz}$ versus those at $18 \mathrm{GHz}$, vertical polarization, from a rectangular area in the Bering Sea-Chukchi Sea-Arctic Ocean region

Figure 15. Scatter plot of emissivities at $37 \mathrm{GHz}$ versus those at $18 \mathrm{GHz}$, vertical polarization, from a rectangular area in the East Siberian and Laptev seas during three consecutive winter months....

Figure 16. Maps of mean annual atmospheric surface pressure for 1979-1982, indicating a large interannual variability

Figure 17. The draft of sea ice along a $1400 \mathrm{~km}$ track in the Beaufort Sea, obtained by upward-looking sonar from the nuclear submarine Gurnard in April 1976.

Figure 18. Coverage of the northern hemisphere during one-half day by the DMSP SSM/I.

Figure 19. The seven-channel SSM/I radiometer ready for placement aboard a satellite.

Figure 20. Scan geometry for SSM/I 43

Figure 21. Geographical areas in the northern and southern hemispheres to be covered by the PODS archive of SSM/I data, which will include microwave brightness, ice concentration, and ice type. 


\section{List of Tables}

Table 1. Seasonal variations of snow and sea ice in the northern and southern hemispheres at the times of maximum extent, in millions of square kilometers.

Table 2. Ice types according to generally used terminology, their thickness, and their classification in passive microwave images

Table 3. Summary of spaceborne systems available for observing sea ice parameters ..................................................... 17

Table 4. SSM/I performance characteristics.................................. 43

Table 5. Processing level definitions .......................................... 44

Table 6. Summary of data sets recommended for archival...................... 45 


\section{Executive Summary}

Sea ice is a fractured aggregate of so-called floes, ranging in size from small fragments to plates measuring several kilometers in diameter. Winds and ocean currents keep the ice in almost continuous motion, pushing it apart and exposing the sea surface, or compressing it with great force, cracking the ice and forming massive pressure ridges tens of meters thick. This ice cover dominates the interaction between the atmosphere and the sea in high latitudes, profoundly influencing the climate of these regions. In summer, the melting ice flushes the sea surface with low salinity water, creating conditions benign to many marine creatures. The potential destructiveness of the ice to the constructions of man severely limits maritime activities and the development of needed natural resources. The exact behavior of this complex and extensive oceanic cover is scientifically important but inadequately known. Direct observations are difficult because of the darkness, remoteness, and natural hazards of that environment. However, many sea ice characteristics are discernible by satellite-borne instruments, and many others are potentially discernible with appropriate research; another valuable contribution of satellites is relaying data from buoys designed to drift with the ice and automatically report oceanic and meteorological conditions. A promising avenue of direct satellite research, surveillance of sea ice by measurement of emitted microwaves, has been established over the past decade. This document examines the benefits of such data and recommends a course for optimum scientific utilization of passive microwave data obtained over the next decade from a Defense Meteorological Satellite.

Sea ice processes occur on time scales ranging from those of the ocean (months to centuries) to those of the atmosphere (hours to years). Thus, observations of sea ice are logistically demanding, as some $10 \%-15 \%$ of the World Ocean must be monitored every few days for decades to record its behavior adequately. Although accurate and economical environmental observations are a considerable challenge, some equally considerable successes in this area have already been posted.

The first satellite to obtain global measurements of thermally emitted microwaves was Nimbus-5, launched in 1972 and carrying a single frequency radiometer (the Electrically Scanning Microwave Radiometer, or ESMR). This satellite produced the first accurate, global, regular data on sea ice extent. This data set also yielded information on ice compactness (concentration), ice age, and surface condition. The Nimbus -5 radiometer was followed by five-frequency, dual-polarization radiometers (the Scanning Multifrequency 
Microwave Radiometer, or SMMR) on Seasat and Nimbus-7. These sensors, which essentially fill the interval to the present time, produced a more powerful data set yielding more detailed information on ice concentration and type. Research extending the interpretation of these data sets is ongoing and productive.

Future observations are important for two reasons: to increase the period of continuous observations so it is long enough for comparison with significant oceanographic and climatic events, and to improve the information that can be derived from these observations for operational and scientific applications. The next system with which such future observations can be made is the Special Sensor Microwave Imager (SSM/I), which is scheduled to fly for several years starting in late 1985 or early 1986 on satellites of the Defense Meteorological Satellite Program (DMSP). Although this sensor was not designed specifically for scientific research on sea ice, its complement of measured frequencies $(19.3,22.2,37.0$, and $85.5 \mathrm{GHz}$ ) will include those most useful for sea ice research. NASA therefore established a Science Working Group to make a detailed assessment of the benefits of the SSM/I data set to science and the requirements imposed by scientific exploitation on the handling and storage of the data.

We of the Science Working Group vigorously recommend acquisition by NASA of data gathered with the SSM/I, processing of the data to obtain sea ice parameters, and archiving of the observations in an optimally accessible form. Specifically we call for

- Archival of daily average brightness temperatures over the polar regions, binned at a grid size of $25 \mathrm{~km}$ for all channels except $85.5 \mathrm{GHz}$, which should be binned at a grid size of $12.5 \mathrm{~km}$. These data, which represent a large volume, are needed for developing new algorithms to derive geophysical parameters from the satellite measurements. Distribution by mail on magnetic tape or optical disk is adequate for this purpose.

- Computation and archiving of sea ice extent, concentration, and ice type derived using algorithms currently under development. These ice parameters should be retained in orbit-swath format and as gridded or mapped averages. Estimates of ice extent should be daily averages at a spatial resolution of $12.5 \mathrm{~km}$; other parameters should be averaged over three days with a grid size of $50 \mathrm{~km}$.

The Science Working Group further supports current activities of the Pilot Ocean Data System (PODS) at the Jet Propulsion Laboratory aimed at 
developing the software necessary to implement these recommendations.

Once this - software- system has been satisfactorily tested with SSM7I data after the launch of the satellite and the validation period of the algorithms, we recommend transfer of the data processing and archival function to the National Snow and Ice Data Center (NSIDC) for routine operations.

In support of these activities, we recommend continued research aimed at improvement and validation of sea ice algorithms. This will require collaboration among various civilian and military groups in the detailed analysis of existing SMMR data, execution of focused in situ measurements on the ice, and examination of information obtained from data buoys, airborne surveillance systems, and upward-looking sonars aboard submarines.

In addition, noting the major potential offered by satellite data from both the SSM/I and synthetic aperture radars (SAR's), we strongly support research using ice data from the Shuttle Imaging Radar (SIR) series, and from the European Space Agency's Earth Remote Sensing Satellite (ERS-1). Finally, noting the importance to all meteorological, oceanographic, and remote sensing studies of the Arctic Buoy Program, which obtains data on air, ice, and oceanic conditions across the entire Arctic, we strongly recommend that this program be maintained through the next decade and strengthened where appropriate. This program will increase the value of SSM/I data to the operational communities, to the sea ice geophysics and climatology communities, and to designers of future earth-observing systems in support of long-term interdisciplinary studies of the land, ocean, atmosphere, and cryosphere. 


\section{Introduction}

Snow and sea ice are the most ephemeral features of the earth's surface. Both undergo large fluctuations annually, and their extent changes over time scales of decades and centuries. Even the large ice sheets of Antarctica and Greenland which vary on time scales of many millennia change rapidly in comparison with the geologic evolution of the earth's crust.

Polar sea ice covers millions of square kilometers of the ocean but has a thickness of only a few meters (Table 1 ). This implies that sea ice has a small heat capacity and that small perturbations in the heat balance at the surface produce large variations in ice extent. In the energetic (visible) part of the solar spectrum the open ocean is nearly black and absorbs most of the incoming radiation. In contrast, the ice cover is nearly white and reflects most of the incoming radiation. Hence the presence or absence of sea ice profoundly alters the heat balance of the atmosphere-ocean system. It has also been demonstrated that snow and ice have a positive feedback effect on the climate; an unusually large ice cover, for instance, will reduce the amount of absorbed solar radiation, creating conditions that will induce a further enlargement of the area covered by ice.

Table 1. Seasonal variations of snow and sea ice in the northern and southern hemispheres at the times of maximum extent (from various sources, Untersteiner, 1984), in millions of square kilometers.

\begin{tabular}{|c|c|c|c|c|c|}
\hline \multirow{3}{*}{$\begin{array}{l}\text { Surface } \\
\text { Area }\end{array}$} & \multirow{2}{*}{$\begin{array}{l}\text { Entire } \\
\text { Globe }\end{array}$} & \multicolumn{2}{|c|}{$\begin{array}{l}\text { Northern } \\
\text { Hemisphere }\end{array}$} & \multicolumn{2}{|c|}{$\begin{array}{l}\text { Southern } \\
\text { Hemisphere }\end{array}$} \\
\hline & & Land & Ocean & Land: & Ocean \\
\hline & 510 & 100 & 155 & 49 & 206 \\
\hline \multirow{2}{*}{$\begin{array}{l}\text { Snow on land } \\
\text { and } \\
\text { sea ice on } \\
\text { the ocean }\end{array}$} & Minimum & 2 & 8 & 14 & 3 \\
\hline & Maximum & 49 & 15 & 14 & 20 \\
\hline \multirow{4}{*}{$\begin{array}{l}\text { Snow and } \\
\text { sea ice } \\
\text { areas } \\
\text { combined }\end{array}$} & Minimum & \multicolumn{2}{|c|}{10} & \multicolumn{2}{|c|}{16.5} \\
\hline & Maximum & \multicolumn{2}{|c|}{64} & \multicolumn{2}{|c|}{34} \\
\hline & Minimum & \multicolumn{2}{|c|}{$4 \%$} & \multicolumn{2}{|c|}{$6.5 \%$} \\
\hline & Maximum & \multicolumn{2}{|c|}{$25 \%$} & \multicolumn{2}{|c|}{$13.5 \%$} \\
\hline
\end{tabular}


Sea ice is an integral component of the global climate system and interacts with both the ocean and the atmosphere. Because of this, longrange climate forecasts will require the inclusion of sea ice within both the climate models and the global observational system. Sea ice also has an immediate impact as an impediment to offshore resource development and shipping - implying the need for routine, synoptic observations and shortterm forecasts of sea ice behavior. Ice advisories and short-term forecasts are issued by the Navy and the National Oceanic and Atmospheric Administration (NOAA), and passive-microwave data are essential to the success of this work.

Research into the dynamic relationships between sea ice and other elements of the climate system is particularly important as we become more aware of the potential for climate change due to short-term effects such as El Niño or more lasting effects such as the increase in atmospheric $\mathrm{CO}_{2}$. In this report we review the status of sea ice research and recommend specific activities related to passive microwave remote sensing from space.

The most difficult aspect of devising a strategy for studying any component of the physical environment is choosing which processes to include or ignore, and the amount of detail to resolve or neglect. Asking the right overall question is generally easy, but asking it in the right way requires that we already have a measure of insight into the nature of the problem. In geophysical and particularly climatological research, it is rarely possible to isolate a single physical process for study. More often, a geophysical measurement is the composite result of many processes acting simultaneously. Therefore, some a priori understanding of the system, derived from past observations and study of various individual phenomena, is required. Because of past research on sea ice processes, including analysis of satellite observations, we have made significant progress toward such understanding. Data from spacecraft have played an essential part in this process, and they will be even more important to future progress. Consequently, we strongly support the acquisition of data from upcoming earth-viewing satellites that will overfly the polar regions. In particular, we expect passive-microwave data to continue to play a central role in sea ice research.

\subsection{Sea Ice}

The formation of sea ice begins with the appearance of individual frazil ice particles on the ocean surface. The frazil particles then aggregate and form a slushy layer called shuga. Further cooling of this initial skim of ice transforms the slushy surface into a more consolidated layer called nilas. 
During the initial stages of freezing and later when a solid layer of ice is advancing downward into the water, some brine is included in the ice: Because the crystallographic structure of ice does not allow the inclusion of non-ice molecules, the brine in sea ice is contained in macroscopic pockets (of millimeter size). In the freezing process, much of the salt dissolved in sea water is rejected, making the bulk salinity of sea ice generally smaller than that of sea water. Rate of freezing and ice salinity are related such that the fastest growing ice has the highest salinity (and vice-versa).

A special phenomenon occurs in the top few centimeters of the ice. Here, progressive cooling causes an upward expulsion of brine which results in a skin of extremely high salinity typically found on newly frozen ice.

The processes by which salts are incorporated in the forming ice, migrate within the ice layer, and, in time, are to a large part returned to the ocean (Untersteiner, 1968; Cox and Weeks, 1974) are complex and extremely important in determining the microwave radiative properties of the ice.

First year ice that survives the summer becomes second year ice. The physical properties of that ice make it distinguishable from older ice only under exceptional circumstances. Therefore, all ice remaining at the end of a melt season is termed multiyear ice. When snow on first year ice begins to melt during the early part of summer, the patchy distribution of melt water with. its lowered albedo causes locally preferential melting. This process continues until autumn freeze-up, and results in an undular relief with some of the surface covered by refrozen meltponds. Each succeeding melt season enhances the relief on the ice surface (hummocks become higher and meltponds fewer) until it reaches equilibrium after a number of years.

As the surface changes from relatively flat for first year ice to hummocks about $1 \mathrm{~m}$ high for well developed multiyear ice, the properties of the nearsurface layer also change. The approximate volume of brine in the top few centimeters of the ice is about $12 \%$ for young ice and diminishes as the ice grows in age and thickness. Although the seasonal snow cover that falls on the ice is originally salt free, it may pick up significant amounts of salt as it is pushed around by the wind.

This age progression is summarized in Table 2. Each change influences microwave radiation emanating from the ice surface. Consequently, in principle, different types of ice can be distinguished by measuring their microwave emissions. In practice, microwave classification is restricted to the four ice types shown in Table 2 , and generally only first year and multiyear ice are distinguished. 
Table 2. Ice types according to generally used terminology, their thickness, and their classification in passive microwave images. The freezing season lasts from early autumn to late spring. Depending on the geographical region. $2 m$ of ice (in some regions even more) can form during that time. Therefore, the thickness of first year ice covers a wide range, depending on the date when a particular surface element began to freeze.

\begin{tabular}{|c|c|c|c|}
\hline \multicolumn{2}{|c|}{ TERMINOLOGY } & THICKNESS & $\begin{array}{l}\text { PASSIVE } \\
\text { MICROWAVE }\end{array}$ \\
\hline New Ice & $\begin{array}{l}\text { Frazil ice (loosely } \\
\text { floating needles } \\
\text { and platelets) } \rightarrow \text { nilas } \\
\text { (first stage of thin } \\
\text { but consolidated ice) }\end{array}$ & $2-10 \mathrm{~cm}$ & New ice \\
\hline Young Ice & & $10-30 \mathrm{~cm}$ & First year ice \\
\hline First Year Ice & $\begin{array}{l}\text { Depending on date } \\
\text { when freezing started }\end{array}$ & $20-200 \mathrm{~cm}$ & \\
\hline Multiyear Ice & Multiyear & generally $>2 \mathrm{~m}$ & Multiyear ice \\
\hline
\end{tabular}

\subsection{Sea Ice Research}

The most fundamental description of the sea ice cover is its mass balance. The mean annual cycle is a result of ice formation (sources), horizontal flux (drift), and melting (sinks). This cycle implicitly contains all the external and internal dynamic and thermodynamic processes affecting sea ice. These processes also affect the underlying sea and the overlying air, and they represent the interactions of sea ice with the climate system. The basic role of sea ice is to restrict heat and mass exchange between the ocean and the atmosphere; ice also modifies forcing of the sea by the wind, and ice forming or melting alters the local brine content of the water column, changing stratification and mixing of the ocean.

In some regions of the World Ocean, sea ice formation is connected to deep convection and the formation of characteristic water masses. It has recently been shown that $75 \%$ of the water masses of the World Ocean acquire their specific properties in an area measuring only $5 \%$ of the surface of the 
World Ocean, and that this small region is located at polar latitudes (Sarmiento and Tottweiler, 1984). The implications of this fact are at present not understood in detail, but the conclusion is inevitable that, on time scales of decades and longer, sea ice, deep circulation of the oceans, and global climate must be intimately related.

For the sake of illustration, an extremely simplified sketch of air-sea-ice interaction in the Arctic (Hunkins, 1983) is shown in Figure 1. Ice transport in the Arctic Basin, as shown in Figures $2 a$ and $2 b$, occurs along the main drift features of the Beaufort Sea Gyre and the Transpolar Drift Stream flowing from the East Siberian Sea toward Fram Strait. The main ice sink (region of ice loss) is the entire width of Fram Strait between Greenland and Spitzbergen. The cold East Greenland Current to the west carries ice far southward to the southern tip of Greenland and beyond, while the warm West Spitzbergen Current to the east melts the ice rapidly, and it engulfs the Svalbard Archipelago only during winter.

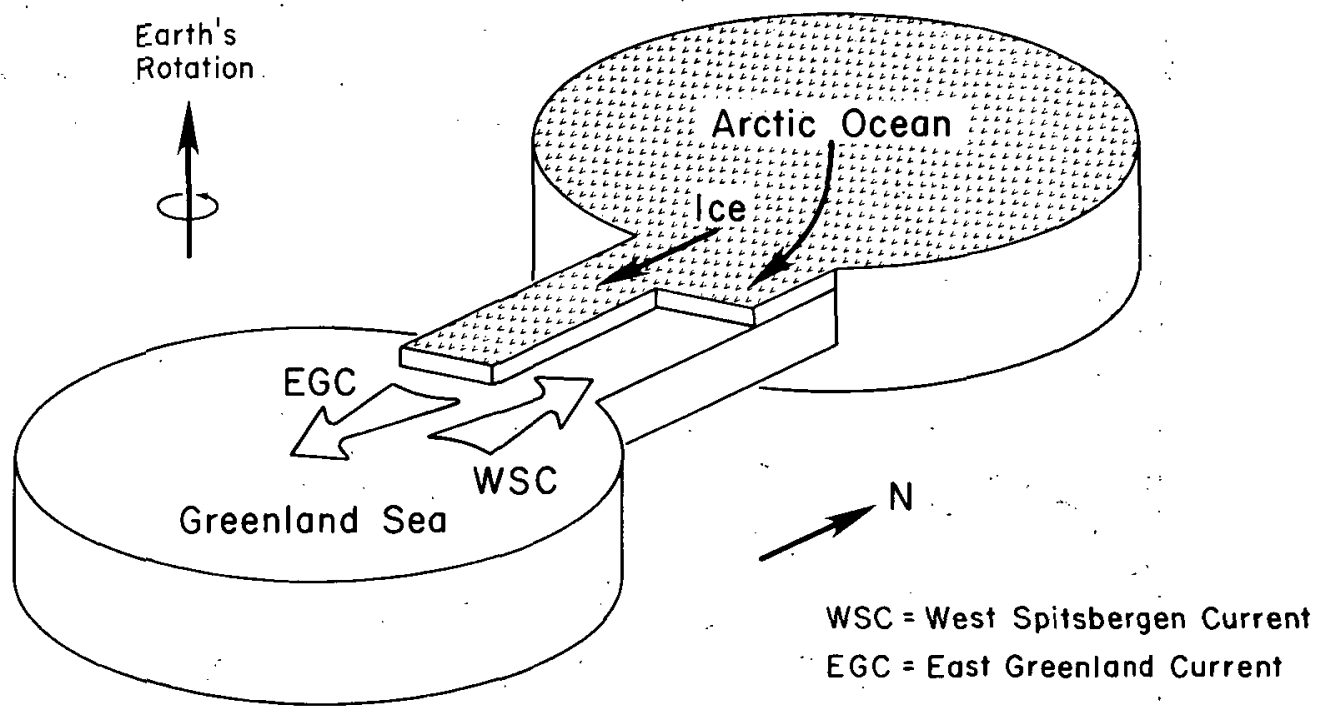

Figure 1. Ice and water exchange between the Arctic and Atlantic oceans viewed as an estuary exchange between two rotating tanks fuled with water of different salinity (higher in the Greenland Sea and lower in the Arctic Ocean). Ice is driven by southward winds across the entire width of Fram Strait, the narrow passage connecting the two basins. On the east side, the ice is slowed by an opposing current and melted by its high temperature (generally a few degrees above freezing). On the west side, the ice drifts with the cold East Greenland Current, and melting begins only at latitudes far south of Fram. Strait. It should be noted that this picture is highly schematic, pertains only to the upper few hundred meters of the ocean, and ignores the water exchange through the Barents Sea, the Canadian Archipelago, and Bering Strait (all of which are much smaller than the exchange through Fram Strait). [from Hunkins, 1.983] 


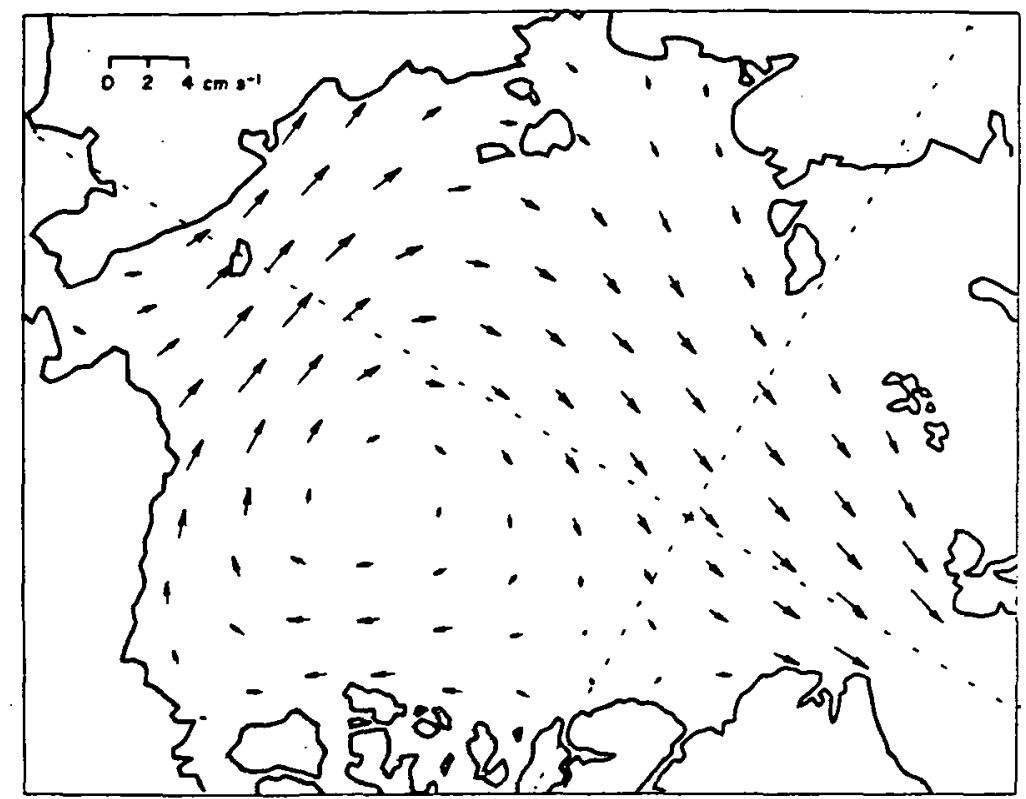

Figure 2a. Ice drift velocity in the Arctic Basin averaged and interpolated over all available data since the drift of Nansen's Fram (1893-1896), including data from the Arctic Data Buoy Program initiated in 1979. The total number of point-displacement years used in constructing this figure is approximately 100. [from Colony and Thorndike, 1984]

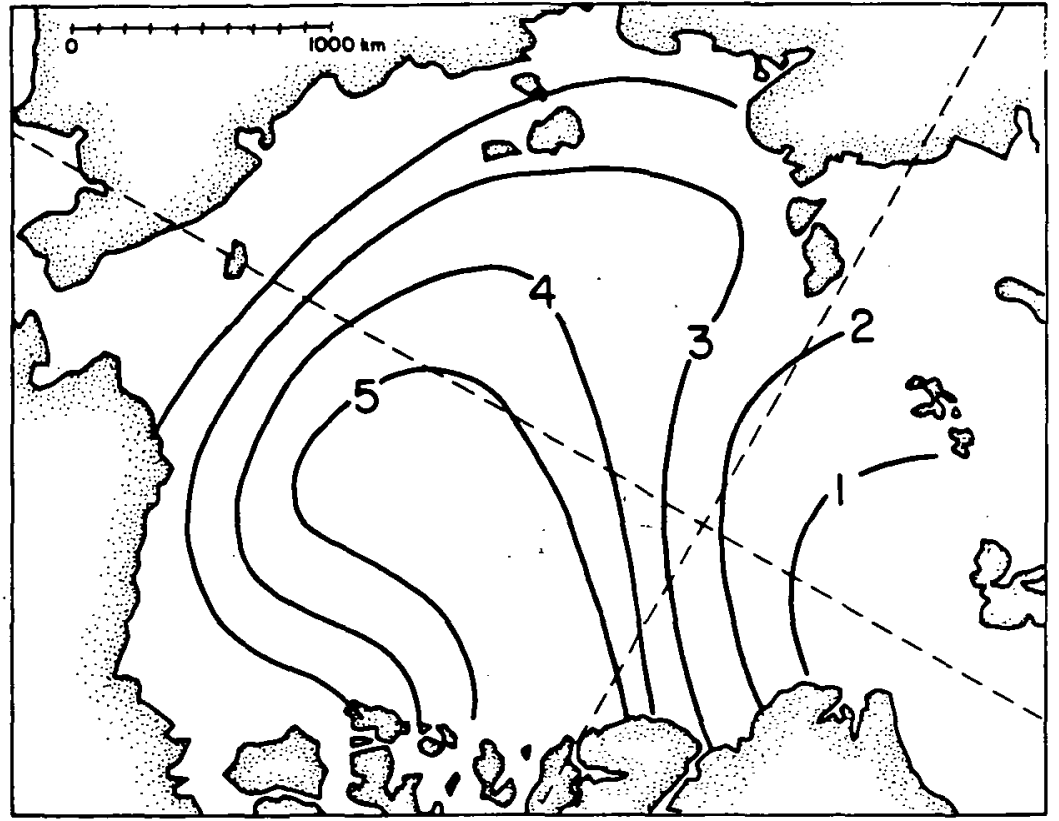

Figure 2b. Given the mean velocity field shown in Figure 2a, it is possible to calculate the "life expectancy" of a piece of ice in the Arctic Basin. The contours shoum here depict the average number of years that it will take for a piece of ice to either melt along the margins of the Arctic Basin or exit through Fram Strait. Such probabilistic data will be extremely useful in conjunction with analyses of passive microwave monitoring of ice types and ice extent. 
Research during the International Geophysical Year (1957-58) and the Arctic Ice Dynamics Joint-Experiment (1972-76) (Pritchard, Ed., 1980) together with data from satellites and the Arctic Data Buoy Program have advanced our ability to model the behavior of large fields of sea ice. Further advance will require linking these models to those of the atmosphere and ocean, and frequent, synoptic observations of sea ice conditions in both polar regions. This is, in essence, the view expressed in the Scientific Plan of the WMO-ICSU World Climate Research Programme (WMO-ICSU, 1981) and its predecessor, the Global Atmospheric Research Programme (GARP, 1975, 1979).

\subsection{Observations}

To understand sea ice behavior and its interaction with the ocean and atmosphere the following measurements are needed:

a. Global measurements at daily intervals. Because sea ice responds rapidly to atmospheric forcing, measurements at a coarse spatial resolution (several kilometers) are adequate. Measured characteristics should include

- Sea ice extent - defined by the boundary between sea ice and ice free ocean.

- Sea ice concentration - the percentage of a specified ocean area that is covered by sea ice.

- Sea ice thickness

- Sea ice type - the percentage of different types of sea ice within a specified area.

- Surface conditions - snow free or snow covered; thickness of snow cover; liquid water content of the snow cover; extent of surface ponding of melt water; surface albedo; surface roughness.

- Surface temperature - and the temperature of overlying atmosphere.

- Surface winds - speed and direction.

- Sea ice motion - to describe overall motion of the ice pack.

- Ocean conditions beneath the ice - currents, salinity, and temperature.

- Cloud cover. 
Many of these measurements can be obtained from satellite passive microwave data.

b. Localized measurements at high spatial resolution in areas of particular interest, such as the marginal ice zone:

- Sea ice motion - detailed measurements of the velocity field of an array of individual ice floes.

- Ics floe sizes - and the location of leads of open water and new, thin ice.

-Intensity of ridging - where the ice has been locally compressed to form ridges above the surface and keels that can extend tens of meters below the surface.

- Icebergs and thick floes of multiyear ice - location, size, and motion.

These measurements also can be made from space using a synthetic aperture radar, which provides all-weather, day/night imagery of sea ice with a spatial resolution of tens of meters (Fu and Holt, 1982; NASA-JPL, 1983). Thus, most required sea-ice measurements can be made from space. However, there is a continuing need for in situ measurements: first, to validate the space measurements and improve our ability to interpret them and, second, to obtain measurements, particularly those of ocean properties below the ice, that cannot be obtained from space. We shall discuss these ancillary measurements further in Section 4.2.

In this report, we are concerned mainly with specifying the requirements for data obtained during SSM/I missions aboard DMSP spacecraft. First, we shall provide a general review of sea ice remote sensing, with a more detailed description of passive microwave measurements. 


\section{Satellite Remote Sensing of Sea Ice}

Until the advent of satellite observations, little quantitative information existed on seasonal and interannual changes in sea ice cover. Remote sensing of sea ice depends on the contrasting appearance of ice and open water over most of the electromagnetic spectrum. The unique value of satellite observations is their ability to provide global coverage of the ice pack at intervals as short as a single day. Satellite data from visible, infrared, and microwave sensors provide the most reliable and regionally uniform information available on the global distribution of sea ice and its seasonal variations. Satellite data on global ice extent now cover more than 10 years, with longer records for individual regions. These data provide realistic ice boundary conditions for atmospheric and oceanic models, and they are used operationally for sea ice forecasting.

\subsection{Visible and Infrared Sensors}

Among the satellite data sets that have proved valuable for sea ice studies are the visible and infrared observations from the Landsat series, NOAA series, and Tiros-N. These images provide fine spatial resolution, but they are obscured by clouds and, in the visible band, unattainable during hours of darkness. Visible imagery with a spatial resolution of $80 \mathrm{~m}$ from the Landsat missions has been available since the launch in July 1972 of Landsat 1. Subsequent Landsat missions had improved resolution (approximately $30 \mathrm{~m}$ ). Individual large ice floes can be identified readily on Landsat images, allowing calculation of their size and shape and estimation of ice concentrations. By identifying individual floes on sequential images, ice floe velocities can be calculated also, but the Landsat repeat interval is much longer than optimal. Also, thin ice is indistinguishable from open water, contributing a significant error, and the Landsat orbit covers only latitudes equatorward of $81^{\circ}$, excluding much of the Central Arctic.

Since the launch of NOAA-2 in October 1972, visible and infrared images have been available from NOAA weather satellites flying in near-polar orbits. NOAA- 2 and the three subsequent NOAA-series satellites carried two-channel Very High Resolution Radiometers (VHRR's), which were succeeded by fouror five-channel Advanced Very High Resolution Radiometers (AVHRR's) aboard NOAA-6 to NOAA- 8 and Tiros-N. AVHRR images have a resolution of approximately $1.1 \mathrm{~km}$, but their usefulness is limited by the obscuring effect of clouds. 


\subsection{Microwave Measurements}

In contrast to visible and infrared data, microwave imagery allows nighttime as well as daytime coverage and is not obscured by clouds; however, it generally has a much coarser resolution. Launch in December 1972 of the Nimbus-5 satellite with the Electrically Scanning Microwave Radiometer (ESMR) introduced global microwave coverage with a spatial resolution of approximately $30 \mathrm{~km}$. The relatively coarse resolution of the sensor allows the creation of maps of the entire polar regions from the microwave data (Figures 3-5) in a way that would be impractical using visible or infrared instruments with their finer resolution.

The value of microwave observations for sea ice studies is due to the sharp contrast between the microwave emissivities of sea ice and open water. At the $1.55 \mathrm{~cm}$ wavelength $(19.35 \mathrm{GHz})$ of the single channel Nimbus-5 ESMR instrument, sea ice has emissivities ranging from 0.84 to 0.95 , roughly twice the emissivity of approximately 0.44 for open water. Consequently, if there is a mixture of sea ice and open water within a given $30 \mathrm{~km}$ resolution cell, the composite emissivity for that resolution cell lies between these limits. This allows the brightness temperatures recorded by the microwave instruments to be converted to approximate sea ice concentrations. Estimated accuracy is approximately $\pm 15 \%$ in regions with predominantly first year ice (Zwally et al., 1983a; Figure 5). Accuracy is less in regions with a mixture of ice types, since brine drainage through the ice during the summer melt results in a generally lower microwave emissivity for multiyear ice than for first year ice.

Multichannel microwave instruments have the potential not only of increasing the accuracy of ice concentration calculations but also of allowing determination of such additional variables as ice temperature, snow cover, multiyear ice fraction, and surface melting. The Scanning Multichannel Microwave Radiometer (SMMR) launched on the Nimbus-7 satellite in October 1978 has ten channels of microwave information. Data from four of the channels are presented in Figure 3. Algorithms to extract various sea ice parameters from the SMMR data have been developed and tested by groups in Norway, Canada, and the United States (Svendsen et al., 1983; Swift et al., 1984; Cavalieri et al., 1984). Arctic Sea ice concentration and multiyear ice fraction derived from the SMMR microwave data are illustrated in Figure 4. A major restriction of the Nimbus-7 SMMR data for studies of the Central Arctic is that the satellite's orbit prevents data collection poleward of $84^{\circ}$, in contrast to the global data collection of the Nimbus-5 ESMR.

Even with the limited length of the data sets available, satellite remote sensing has already made substantial contributions to our knowledge of sea 
$1.7 \mathrm{~cm}$ HORIZONTAL

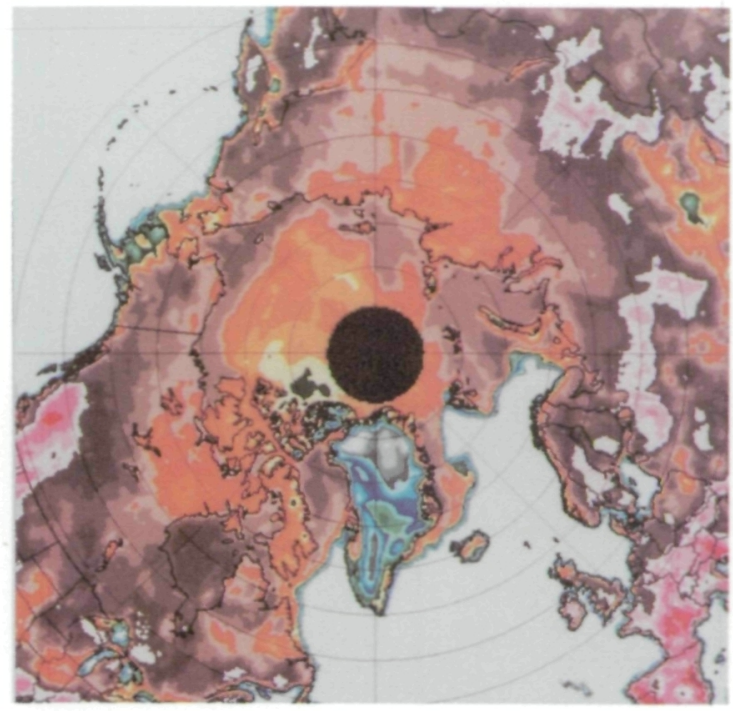

\section{$0.81 \mathrm{~cm}$ HORIZONTAL}

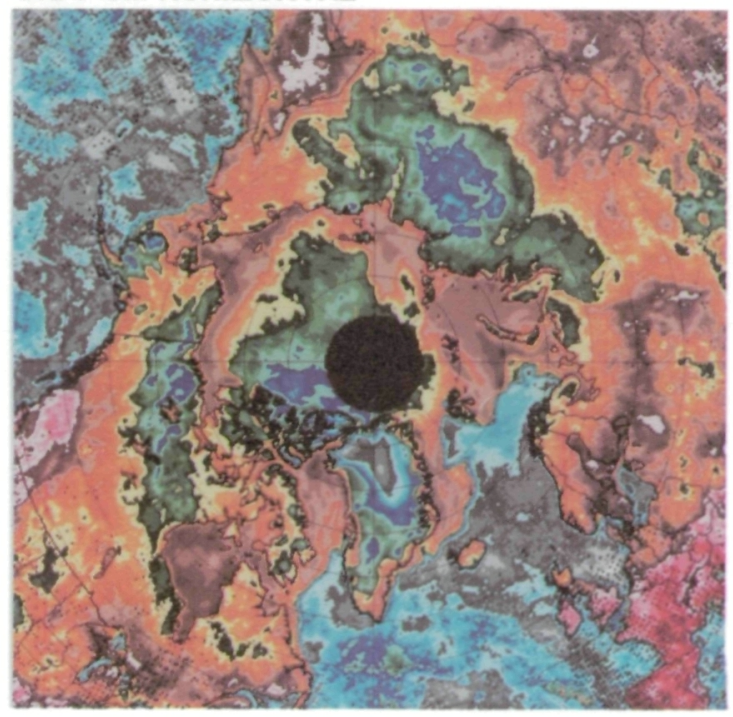

\section{$1.7 \mathrm{~cm}$ VERTICAL}
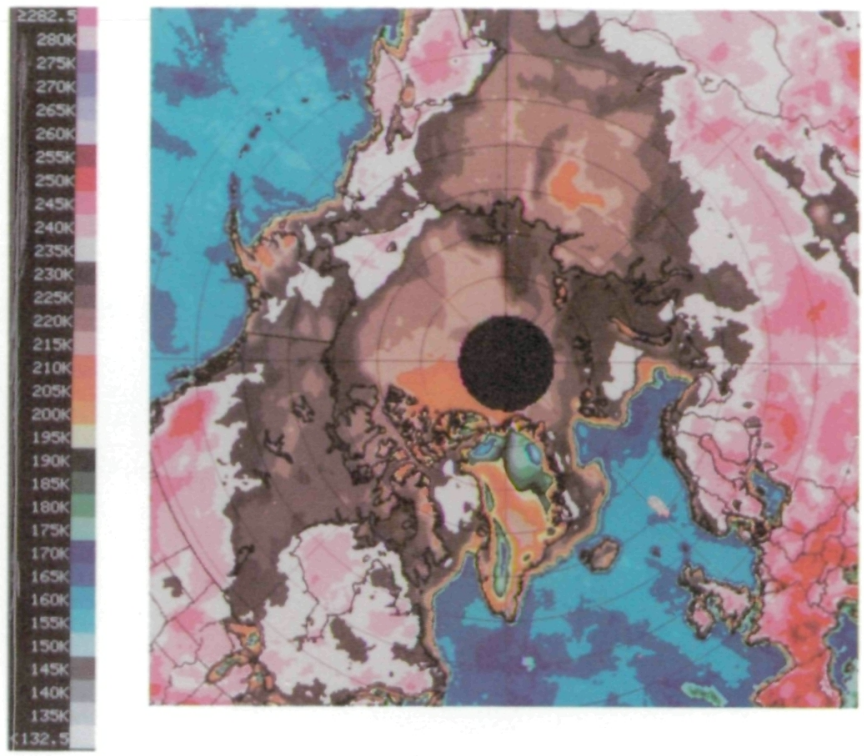

\section{$0.81 \mathrm{~cm}$ VERTICAL}

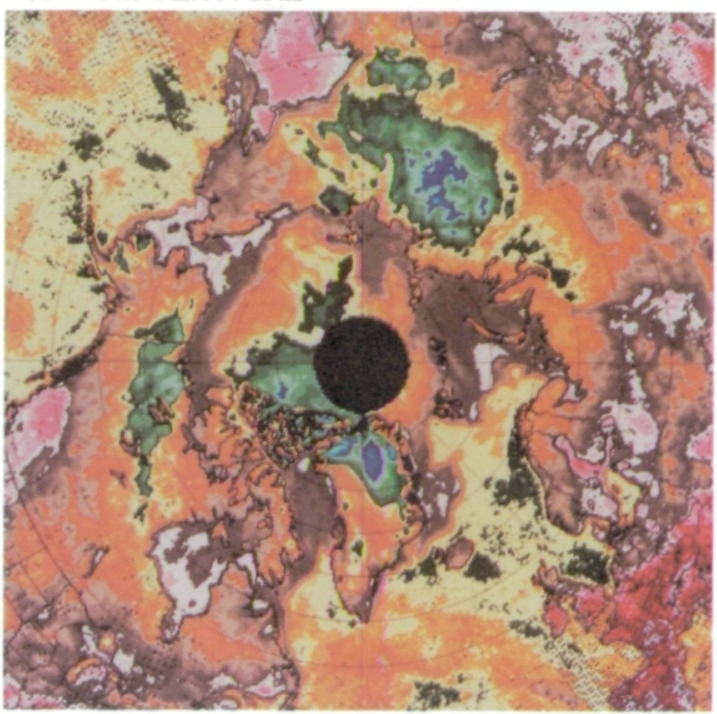

Figure 3. Nimbus-7 SMMR brightness temperature images of the north polar region as observed during February 3-7, 1979, at $18 \mathrm{CHz}(1.7 \mathrm{~cm})$ and $37 \mathrm{GHz}(0.81 \mathrm{~cm})$ for both horizontal and vertical polarizations. The $18 \mathrm{GHz}$ data illustrate the sharp contrast, about $50 \mathrm{~K}$, between sea ice and water, whereas the $37 \mathrm{GHz}$ data show a variation of about equal magnitude across the pack ice itself. Comparison of the polarizations shows a substantial decrease in the contrast between the vertical and horizontal components for both frequencies over ice-covered regions compared with the ice free oceans. These differences are used to determine the areal concentration (compactness) of the ice cover and the ice type. [from Cavalieri et al., 1984] 
(a)

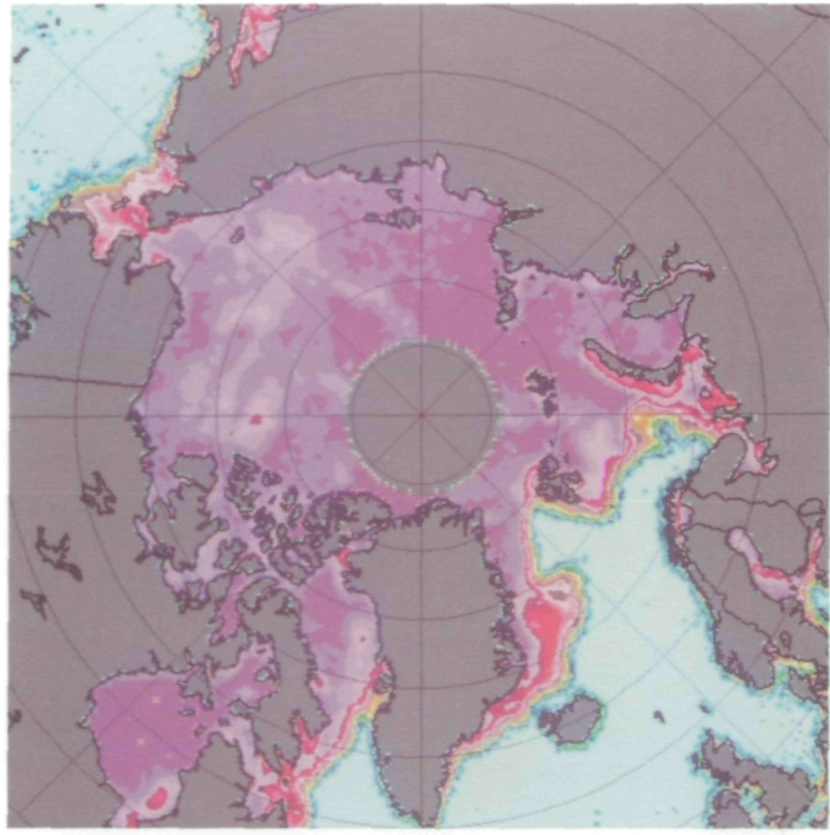

$100 \%$
$96 \%$
$92 \%$
$88 \%$
$84 \%$
$80 \%$
$76 \%$
$72 \%$
$68 \%$
$64 \%$
$60 \%$
$56 \%$
$52 \%$
$48 \%$
$44 \%$
$40 \%$
$36 \%$
$32 \%$
$28 \%$
$24 \%$
$20 \%$
$16 \%$
$12 \%$
$8 \%$
$4 \%$
$0 \%$

(b)

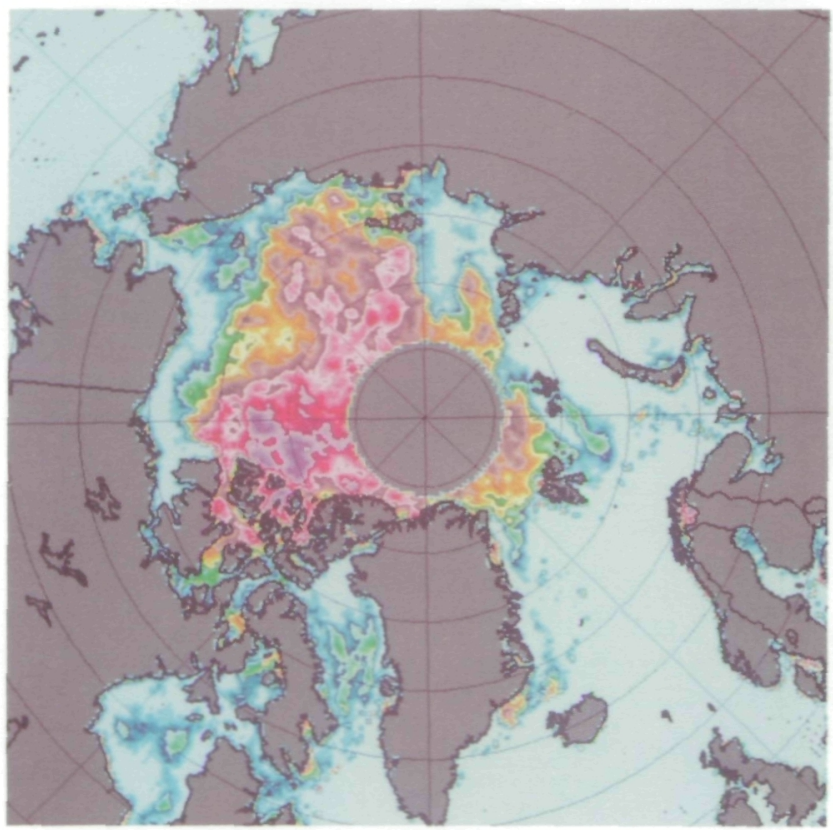

$0 \%$

Figure 4. Polar images of Arctic Sea ice concentration (a) and multiyear ice fraction (b) derived from Nimbus-7 SMMR data for the period February 3-7, 1979. [after Cavalieri et al., 1984] 
O० LONGITUDE

$50^{\circ} \mathrm{S}$. LATITUDE

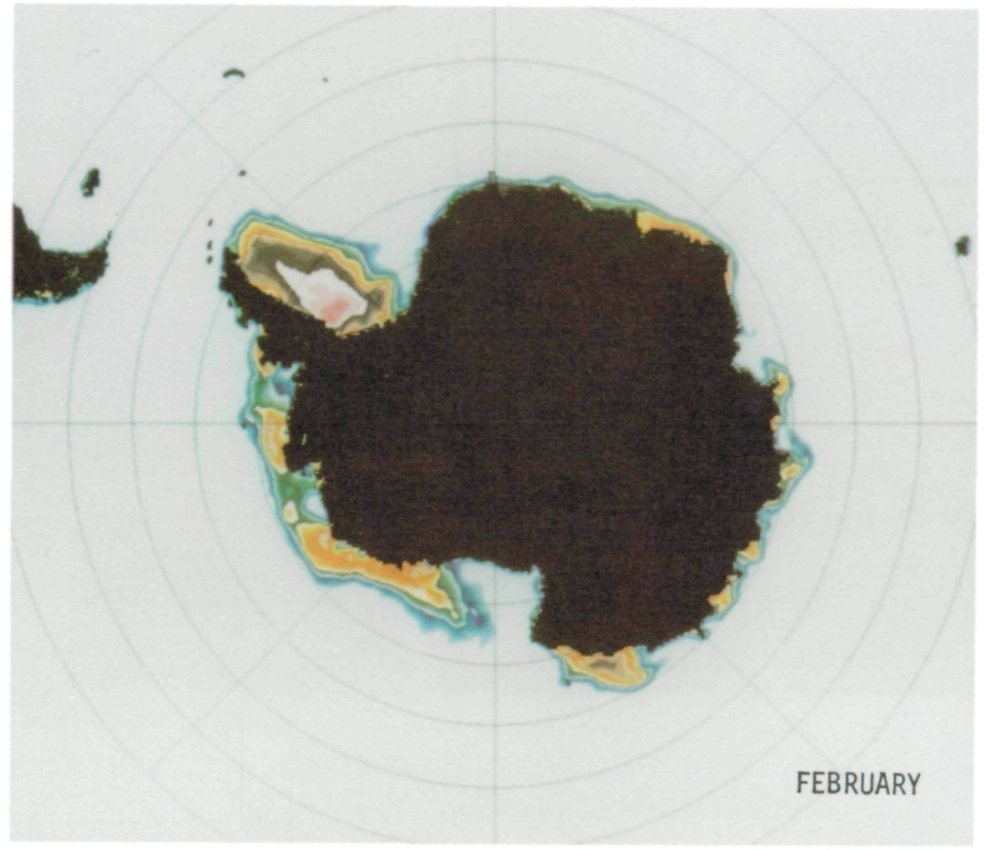

$100 \%$

$80 \%$

$64 \%$

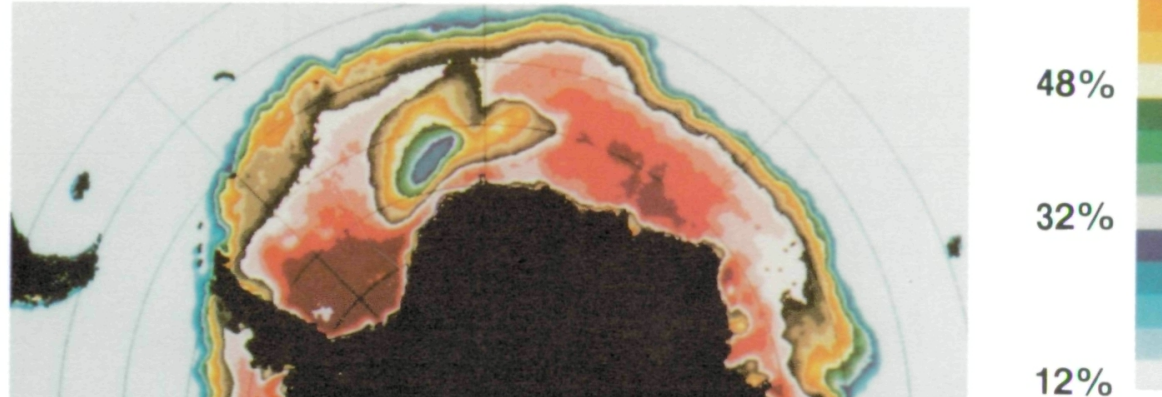

Figure 5. Southern Ocean ice concentration in percent derived from the singlefrequency radiometer on Nimbus-5 (Zwally et al., 1983a). The months of minimum (February) and maximum (October) ice extent are shoum. In each case data are averaged over the indicated month and then over the years 1973-1976. The October results show a large area of low mean concentration near the Greenwich Meridian. This feature is called the Weddell polynya; it was observed in 1974-1976 but not in 1973. 


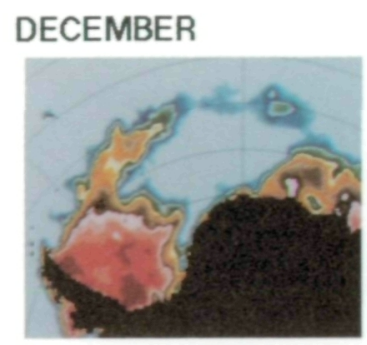

\section{FEBRUARY}

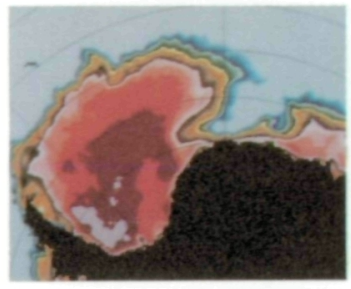

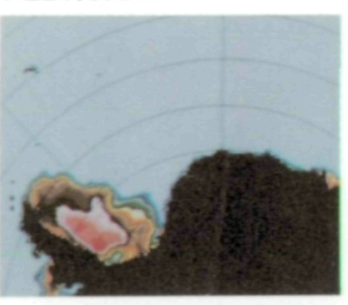

AUGUST

APRIL

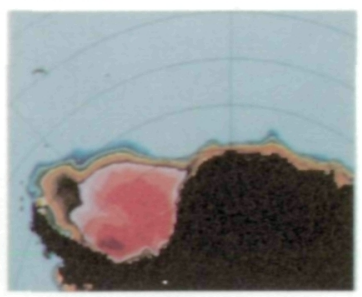

OCTOBER
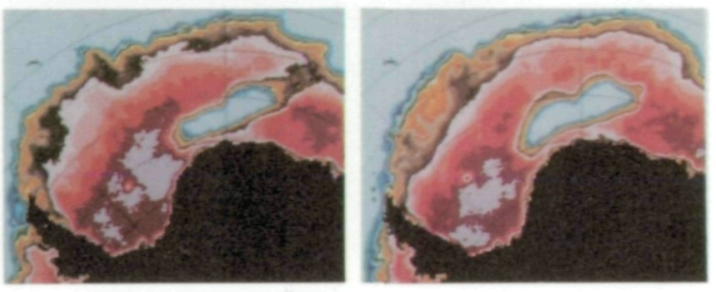

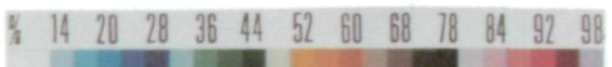

JANUARY 1, INITIAL CONDITIONS

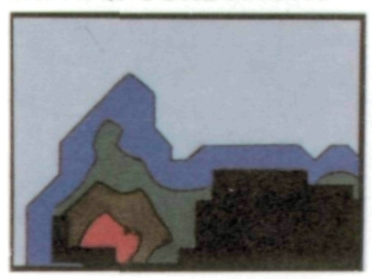

APRIL 15

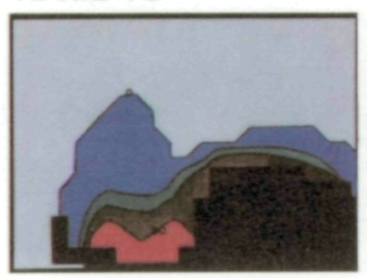

JUNE 15

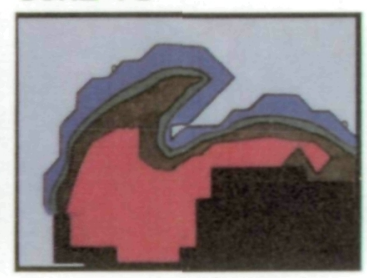

JULY 1

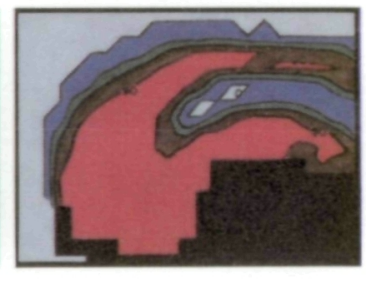

RESULTS OF A COMPUTER MODEL DRIVEN BY MEAN CLIMATE DATA

Figure 6. Formation of the Weddell polynya; satellite observations and results of a computer model driven by mean climate data. Monthly averaged microwave brightness data from Zwally et al. (1983a) taken by Nimbus-5 during the growth of the sea ice cover in the Weddell Sea clearly show the formation of a large polynya, a body of open water surrounded by ice. Numerical simulations from Parkinson (1983) of the same region also demonstrate a tendency toward polynya formation. The huge polynya was first observed by Nimbus-5 in 1974, and other satellites in subsequent years. Its size and exact location vary from year to year. 
ice and its interannual variations. For instance, analysis of satellite data by Zwally et al. (1983b) to determine the seasonal cycle of sea ice on the Southern Ocean for the ten-year period 1973-1982 has revealed large regional variability, a significant decrease in mean ice extent during the mid-1970's (earlier reported by Kukla and Gavin, 1981), and a rebounding of the ice cover in subsequent years (Figure 7). Additional data and studies of this type are needed for determining long-term trends and for understanding the causes of observed interannual variability.

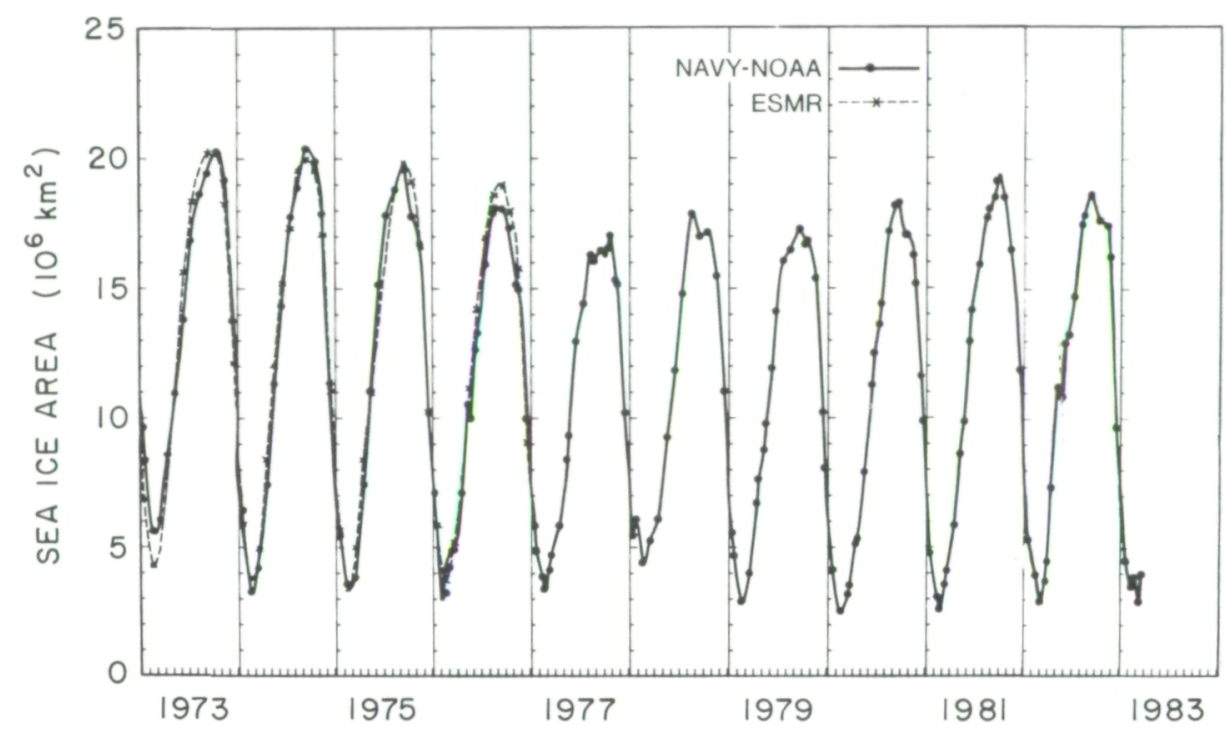

Figure 7. A 10year time series of antarctic sea ice extent (Zwally et al., 1983b). The total area containing sea ice was estimated from satellite passive-microwave measurements. Superimposed on the annual cycle, there was a significant decrease in sea ice extent during the late 1970's. There has been some recovery in recent years, but not to the high values of the early 70's. Extended observations are needed to reveal the causes of these long-term changes in sea ice extent and their relationship to climate.

Satellite data have also revealed such puzzling phenomena as the wintertime existence of the Weddell polynya, a large region of open water in the midst of the Southern Ocean pack ice, visible in Figure 5 (Zwally and Gloersen, 1977; Gordon, 1978; Carsey, 1980). This has, in turn, prompted numerical modeling studies which have furthered our understanding of the polynya and its oceanographic and atmospheric interactions (Martinson et al., 1981; Hibler and Ackley, 1983; Parkinson, 1983). Figure 6 shows a comparison of satellite observations and results from one of the modeling studies (Parkinson, 1983). 
Active microwave imagery is obtained by spaceborne synthetic aperture radar systems (SAR). This data source is also of value for sea ice studies, as has been verified abundantly with the short but useful data set collected by NASA's Seasat in June-October 1978. The Seasat SAR operated at a wavelength of $23.5 \mathrm{~cm}(1.275 \mathrm{GHz})$ and produced images which, like the passive microwave images of the ESMR and SMMR, are not obscured by clouds and have a resolution of $25 \mathrm{~m}$, considerably finer than that of other spaceborne microwave sensors. SAR imagery can also reveal details of ice morphology, but the greatest utility of SAR data is in measuring small-scale motion of the ice (Hall and Rothrock, 1981). First year and multiyear ice are not distinguished easily at the long Seasat wavelength; in situ backscatter data indicate that a radar carrier frequency higher than $10 \mathrm{GHz}$ is required for unambiguous determination of ice type.

Satellite data have also been used extensively in descriptive observational studies (e.g., Streten, 1973; McNutt, 1981; Cavalieri et al., 1983; Zwally, et al., 1883a) and in studies of the relationship between the monthly and the interannual variations of the sea ice cover and the atmospheric wind and temperature fields and/or oceanic fields (e.g., Budd, 1975; Ackley and Keliher, 1976; Walsh and Johnson, 1979; Cavalieri and Parkinson, 1981; Gordon, 1981; Parkinson and Cavalieri, 1982). They are well recognized as the most uniform and consistent data sets available for sea ice. However, the use of these data sets for climate studies is limited severely by their brevity, and their usefulness would be increased by information from the SSM/I program.

The methods available for remotely sensing sea ice from space, and their suitability for specific purposes, are summarized in Table 3. 
Table 3. Summary of spaceborne systems available for observing sea ice parameters.

\begin{tabular}{|c|c|}
\hline Parameter & Comments \\
\hline Ice Extent & $\begin{array}{l}\text { Visual: High resolution, accurate; limited by clouds } \\
\text { and darkness. Partial remedy: minimum brightness } \\
\text { technique to eliminate clouds (but not darkness). } \\
\text { In the case of Landsat, poor geographic coverage. } \\
\text { Infrared: Good resolution and accuracy; limited } \\
\text { by clouds and large atmospheric effects. } \\
\text { Partial remedy: minimum brightness technique } \\
\text { as above, but problems with atmospheric effect } \\
\text { and low SST contrast during the warm season } \\
\text { remain. } \\
\text { Passive Microwave: Lower but useful spatial } \\
\text { resolution, no effect of darkness, only small } \\
\text { effects of atmospheric conditions. } \\
\text { Synthetic Aperture Radar: Very high resolution, } \\
\text { all weather and seasons; occasional problems } \\
\text { with open water/new ice discrimination; high } \\
\text { cost of data processing. Only limited data set } \\
\text { available for research from Seasat. }\end{array}$ \\
\hline Ice Concentration & $\begin{array}{l}\text { Visual: Same as ice extent. } \\
\text { Infrared: Same as ice extent. } \\
\text { Passive Microwave: Similar to ice extent; some } \\
\text { unresolved questions about accuracy, especially } \\
\text { in summer. } \\
\text { Synthetic Aperture Radar: Same as ice extent, } \\
\text { except that small leads are not resolved and } \\
\text { their contribution to the total open-water is } \\
\text { not known. }\end{array}$ \\
\hline $\begin{array}{l}\text { Ice Type } \\
\text { (here limited to mean } \\
\text { the distinction } \\
\text { between first year } \\
\text { and multiyear ice) }\end{array}$ & $\begin{array}{l}\text { Visual: No use. } \\
\text { Infrared: Possible use in relating ice thickness } \\
\text { to surface temperature, but rendered operationally } \\
\text { uncertain because of overwhelming effect of unknown } \\
\text { snow cover. } \\
\text { Passive Microwave: Very useful in principle, but } \\
\text { existing algorithms give results at odds with other } \\
\text { data. Severe problem with obtaining independent } \\
\text { verification (ground truth). } \\
\text { Synthetic Aperture Radar: Research results to date } \\
\text { indicate that a SAR system with a higher carrier } \\
\text { frequency, C-band or X-band, would be effective. }\end{array}$ \\
\hline $\begin{array}{l}\text { Ice Thickness and } \\
\text { Thickness Distri- } \\
\text { bution }\end{array}$ & No spaceborne system available. \\
\hline
\end{tabular}




\section{Methods of Passive Microwave Remote Sensing}

In this section we summarize methods currently in use and under development for observing sea ice by means of its electromagnetic emissions in the microwave spectral range.

\subsection{Background}

All matter radiates electromagnetic energy as a consequence of molecular interaction. The energy is emitted over a range of wavelengths, the precise mix being determined by the viewing angle, molecular composition, temperature, and material structure. Ice and water have distinct emission signatures, primarily because of differences in the way molecules are arranged in each. Moreover, different ice samples can have distinct signatures, partly because of temperature differences and partly because of differences in texture and impurity content. Snow density, grain size, surface roughness, brine content, and the degree of wetness all influence the radiated energy, and they influence it differently at different wavelengths. Thus, by sampling an appropriate suite of wavelengths, the ice cover can be distinguished from open water and classified according to its surface and near-surface characteristics.

Over sea ice, passive microwave data can be used to distinguish water from ice and characterize the major ice types (Table 2): new ice, a few centimeters thick; first year ice, generally snow covered and up to $2 \mathrm{~m}$ thick; and multiyear ice, which has survived at least one summer, has undergone deformation and cracking, and is of variable thickness with a more or less undulating surface. Multiyear ice is also distinctive in having a lower salinity than younger ice, and this gives it a distinctive microwave signature. In principle, the relative concentrations of water and each of the major ice types can be distinguished by passive microwave data at appropriate wavelengths. Major problems occur, however, during the summer when the existence of water on the ice surface significantly affects the microwave emissions (Figure 8). This problem is currently under investigation by several NASA- and Navy-funded researchers (Comiso et al., 1984; Carsey, 1984), and in the Canadian Atmospheric Environment Service.

Over land, passive microwave data can potentially distinguish the extent, water equivalent, and onset of snow melt for seasonal snow cover (Kunzi et al., 1982), and the regions where summer melting occurs on the terrestrial ice sheets of Greenland and Antarctica (Zwally and Gloersen, 1977). Some of these applications are still research topics, but they promise to become 

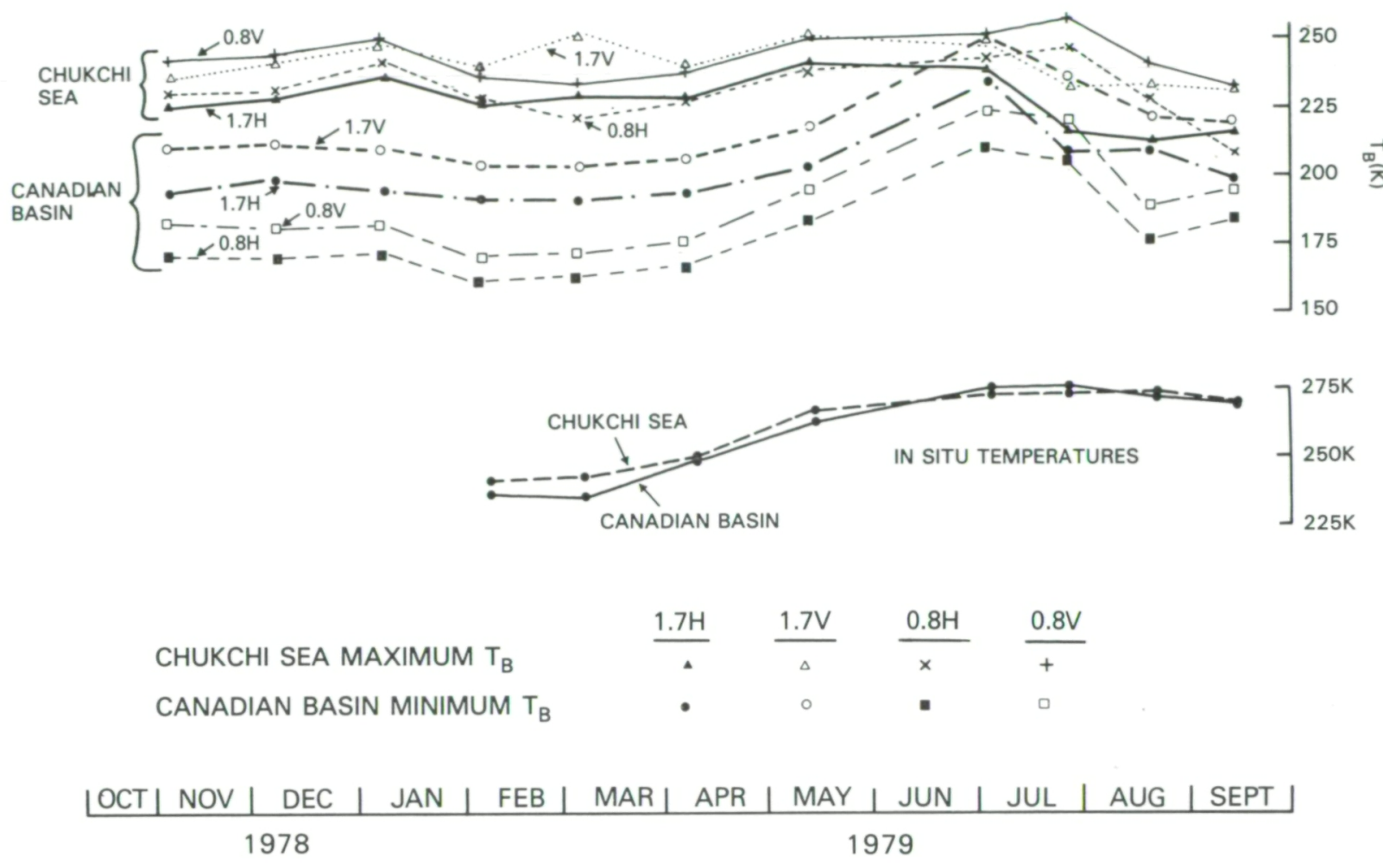

Figure 8. Nimbus-7 SMMR horizontally and vertically polarized brightness temperatures at the 0.81 and $1.7 \mathrm{~cm}$ wavelengths over the annual cycle 1978/79. The maximum brightness temperatures observed in the Chukchi Sea correspond to microwave emissions from first year ice, whereas the minimum brightness temperatures observed in the Canadian Basin correspond to emissions from largely multiyear ice. The distinction between first year ice and multiyear ice is maintained throughout most of the year, but becomes impossible during the summer months because of surface melt conditions. In situ temperatures obtained from arctic data buoys illustrate the seasonal change in temperature for each region. [from Cavalieri et al., 1984]

operational tools within the near future. In addition, it may be possible to deduce snow accumulation rates over the polar ice sheets (Zwally, 1977; Rotman et al., 1982).

The spatial resolution of a microwave sensor increases as the wavelength decreases or as the antenna size increases. Thus, high resolution can readily be obtained in the visible and infrared bands, but this short wavelength radiation is strongly affected by atmospheric conditions, particularly clouds. Microwave radiation lies in the frequency range of $1-300 \mathrm{GHz}$ (wavelengths of about 30 to $0.1 \mathrm{~cm}$ ). It penetrates clouds and can provide all-weather, 
day/night synoptic measurements of several parameters of the earth's surface and atmosphere (Njoku, 1982). The first satellite sensor to provide global information on ice extent was the Electrically Scanning Microwave Radiometer, launched by NASA aboard Nimbus-5 in December 1972. It measured horizontally polarized radiation at $19.35 \mathrm{GHz}$ with a spatial resolution of about $30 \mathrm{~km}$ and had a useful swath width of $1400 \mathrm{~km}$. Because measurements were made at only one frequency, there is ambiguity in data interpretation. However, estimates of ice concentration can be made to an accuracy of about $\pm 15 \%$ in areas where the ice cover is more or less homogeneous.

The quality of ESMR data deteriorated after 1976, but they were still used for operational ice forecasting by the Navy/NOAA Joint Ice Center until 1983. In October 1978, the Scanning Multichannel Microwave Radiometer was launched aboard Nimbus-7. It has provided excellent data since then and is expected to continue operating into the late 80's. The SMMR acquires data in both vertical and horizontal polarizations at five frequencies: 6.6, 10.7, 18, 21 , and $37 \mathrm{GHz}$. Spatial resolution ranges from 30 to $150 \mathrm{~km}$, depending on frequency, and swath width is $780 \mathrm{~km}$. Data from the 18 and $37 \mathrm{GHz}$ channels are used to obtain both the total concentration of sea ice and the fraction of multiyear ice (Cavalieri et al., 1984).

Starting in 1985 or early 1986, the U.S. Defense Meteorological Satellite Program will launch a series of spacecraft that will carry the Special Sensor Microwave/Imager, a scanning microwave radiometer that will collect data from a $1300 \mathrm{~km}$ wide swath in both vertical and horizontal polarizations at $19.35,37$, and $85.5 \mathrm{GHz}$ and at $22.235 \mathrm{GHz}$ in vertical polarization only. Spatial resolution will be between 12 and $50 \mathrm{~km}$, depending on frequency.

\subsection{Derivation of Sea Ice Characteristics}

Conversion of passive microwave data to sea ice characteristics relies on the basic equation of microwave radiometry (Grody, 1976), which evaluates brightness temperature $\left(T_{B}\right)$ for frequency $i$ and polarization $j$

$$
T_{B i j}=\varepsilon_{i j} T_{0}+t_{i}\left[2 T_{0}-\varepsilon_{i j}\left(T_{a}+T_{0}\right)\right]+\left(1-\varepsilon_{i j}\right) T_{s p i},
$$

where $\varepsilon_{i j}$ is the emissivity, $t_{i}$ is the atmospheric opacity, $T_{a}$ is the mean atmospheric temperature, $T_{o}$ is the surface temperature, and $T_{s p i}$ is the brightness of outer space. If the atmosphere and the outer space terms are neglected, a simplified expression is obtained:

$$
T_{B i j}=\varepsilon_{i j} T_{0} .
$$

where the different values of $\varepsilon_{i j}$, about 0.5 for open water and 0.8 to 0.95 for the different ice types, produce the ice-water and ice type contrasts. In gen- 
eral, the emissivity is that of an aggregate of surface materials; specifically, for $n$ ice types

$$
\varepsilon_{i j} T_{o}=\sum_{k=1}^{n} C_{k} \varepsilon(k)_{i j} T_{o}(k)
$$

where

$$
\sum_{k=1}^{n} C_{k}=1
$$

and $T_{0}(k)=T_{0}$ unless a different thermometric temperature is assigned to each ice type. The microwaves emitted at shorter wavelengths originate nearer the surface and are consequently more affected by the thermometric surface temperature.

\subsubsection{Single frequency methods}

Algorithms designed to extract ice concentration and ice type from satellite passive microwave data have been developed for the Nimbus-5 ESMR and the Nimbus-7 SMMR instruments. For ESMR data, the algorithm derives ice concentration from observed radiance by linear interpolation between the radiance of open water and that of fully consolidated sea ice (Gloersen et al., 1974; Comiso and Zwally, 1982; Carsey, 1982). From Eq. 3, the ice concentration $C_{I}$ is

$$
C_{I}=\frac{T_{B}-T_{o w}}{\varepsilon(I) T_{e f f}-T_{o w}},
$$

where $T_{B}$ is the observed brightness temperature, $T_{o w}$ is the brightness temperature of the water, $T_{\text {eff }}$ is the effective thermometric (or physical) temperature of the ice, and $\varepsilon(I)$ is the emissivity of the ice. The dependence of surface temperature on location and season is taken from climatological data. Equation 5 implicitly assumes a unique value of ice emissivity. This is approximately true if one ice type predominates, as in Antarctic waters, where ESMR data have been used to derive a four-year time series of ice cover (Zwally et al., 1983a). Where there are two or more ice types, errors in estimated ice concentration can become large.

The single wavelength of the ESMR limits its ability to distinguish between different ice types, but in certain seasons and locations the relative amounts of first year and multiyear ice can be estimated if the total ice concentration is known (Gloersen et al., 1978; Carsey, 1982). As an example, the amount of ice to survive the summer can be estimated by analyzing the increase in $T_{B}$ when the mixture of multiyear ice and open water is approximately replaced by a mixture of multiyear ice and new ice (Carsey, 1982). 
This technique was used to compile Figure 9 showing the four-year mean of multiyear ice concentration in the Arctic at the beginning of the freezing season.

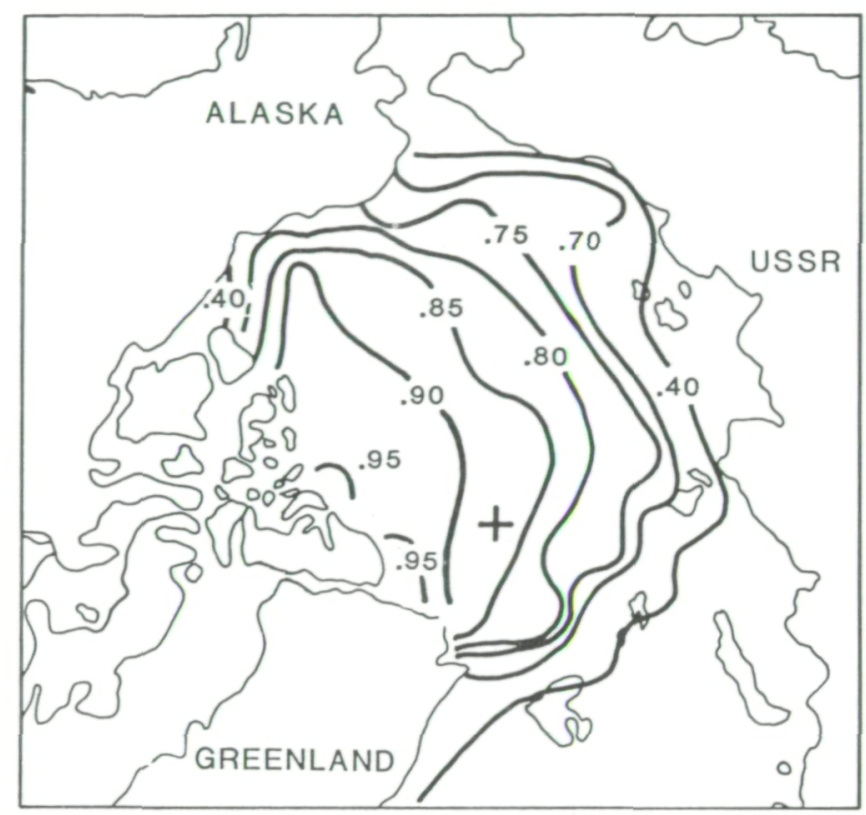

Figure 9. Arctic ice concentration at summer's end averaged over 1973-1976. This result is obtained from Nimbus -5 data by interpreting the change in microwave brightness when the water between multiyear ice floes in August freezes to become the matrix of first year ice cementing the pack together in winter. This plot shows the fraction of multiyear ice at the onset of the cold season.

One channel of data can also provide an estimate of the fractional area covered by freshwater meltponds during the early summer when the ice surface supports a relatively large percentage of such puddles. The area covered by meltponds is needed to improve estimates of surface albedo which, in summer, is largely controlled by the area of the darker puddles; small changes in this albedo are significant both in ice balance models (Maykut and Untersteiner, 1971) and in climate models. July, the period of maximum meltpond coverage, is also the period of minimum $T_{B}$, since the bright exposed ice shares the surface with low-radiance meltponds and leads (Carsey, 1984). The area of exposed ice, $A_{n}$, is computed by

$$
A_{n}=\frac{T_{B}-T_{o w}-T_{a}}{T_{o w}-T_{B h}},
$$


where $T_{o w}$ is the brightness of the lead, $T_{B h}$ the brightness of the exposed ice, and $T_{a}$ the contribution of the atmosphere to $T_{B}$. The area occupied by leads is derived by calculating the amount of ice to survive the melt season by the method described above (Carsey, 1982) and correcting this value for an assumed rate of lateral ablation during the melt season. Finally, the surface albedo is calculated by attributing specific albedos to the ponds, leads, and exposed ice. The many assumptions generate unknown errors, but a first estimate of albedo can be derived. Figure 10 shows Arctic-wide surface albedo for the day of locally maximum ponding (near July 14).

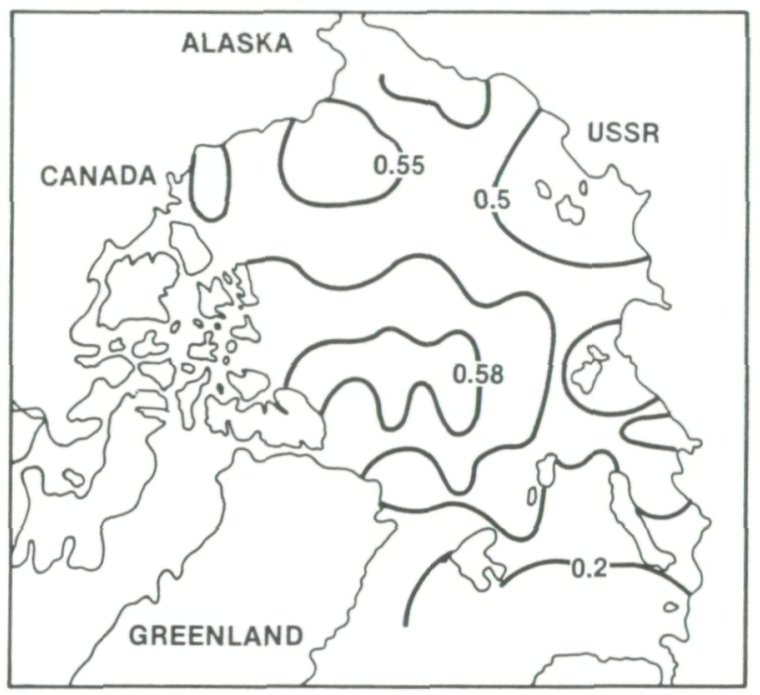

Figure 10.

The inferred cloudy sky surface albedo for the period of maximum meltpond coverage (midJuly) in 1974. This result is obtained by observing directly via the microwave record the amount of exposed ice. Remotely sensed data on ice concentration. and ice age (type) along with surface winds and ice displacement derived from data buoys will provide the key to determining the overall ice balance mentioned in Section 1. Efforts are under way to increase the sophistication of the buoys and provide additional data for the calibration of remote sensing instruments.

\subsubsection{Multifrequency methods}

With the launch of the Seasat and Nimbus-7 SMMR's in 1978, ten channels of dual-polarized, radiometric brightness temperatures at five wavelengths became available for improving ice concentration determinations. The microwave spectra of first year ice, multiyear ice, and ice free ocean shown in Figure 11 were obtained with the Nimbus-7 SMMR, and demonstrate the microwave characteristics of each sample over the range of SMMR wavelengths. In the figure, brightness temperatures for each of the ten SMMR channels are plotted for three regions in the Arctic. "A" corresponds to a region of consolidated first year ice in Baffin Bay, " $\mathrm{B}$ " to a region of largely multiyear ice in the Canadian Arctic, and " $\mathrm{C}$ " to a region of ice-free water in the Norwegian Sea. 


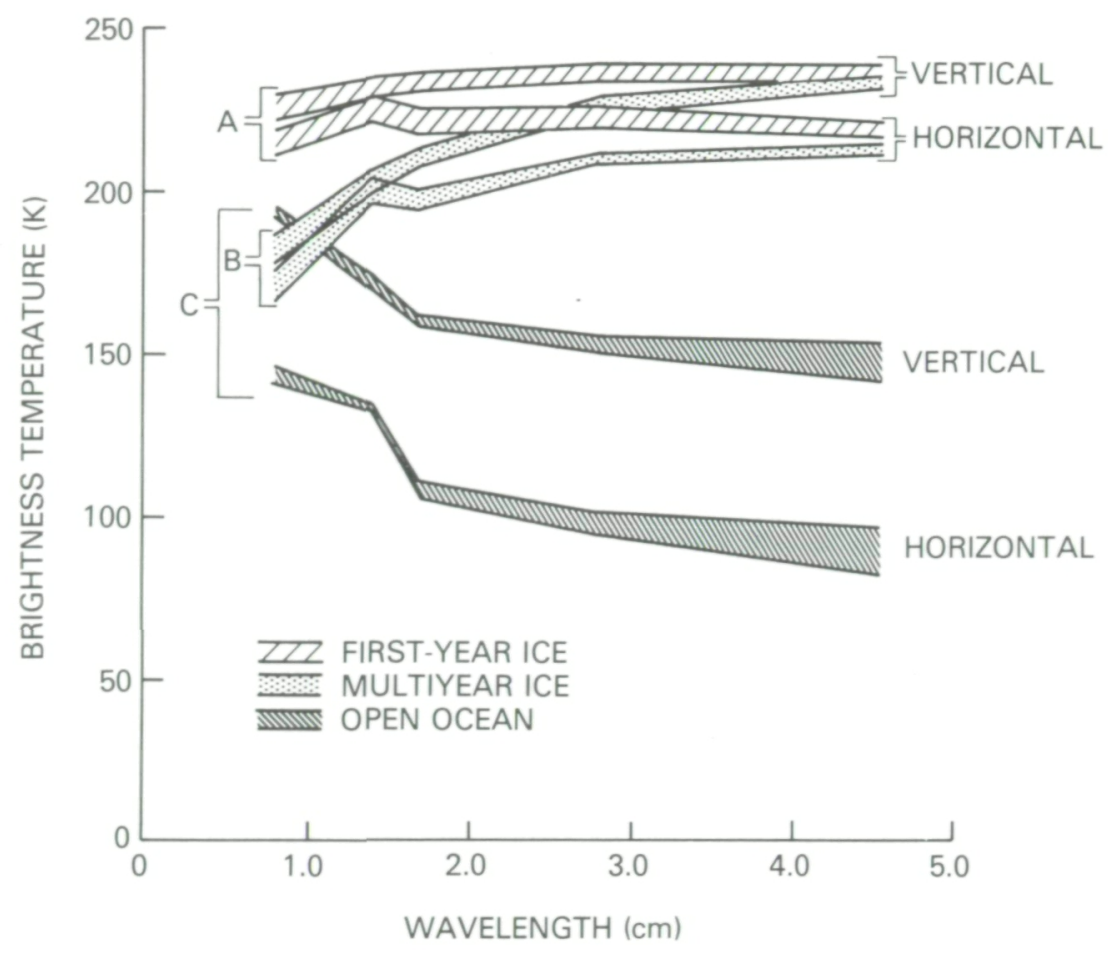

Figure 11. Microwave brightness temperatures of sea ice and ice-free (open) ocean as measured by each of the 10 Nimbus-7 SMMR channels in three regions of the Arctic during February 3-7, 1979. " $A$ " corresponds to a region of consolidated first year ice in Baffin Bay. " $B$ " to a region of largely multiyear ice in the Canadian Arctic, and " $C$ " to a region of icefree ocean in the Norwegian Sea. Hatched bands indicate plus and minus one standard deviation about the mean. [from Cavalieri et al., 1984]

The six spectra in Figure 11 illustrate two important characteristics. The first is that the difference between the vertical and horizontal brightness temperatures is consistently greater for open water than for ice types at all wavelengths. The second is that the difference in brightness temperature between the first year and multiyear ice increases with decreasing wavelength, because this difference arises from scattering of the upwelling microwaves by the air bubbles included in multiyear ice. It is these two microwave characteristics that form the basis of a multichannel algorithm developed by Cavalieri et al. (1984) for determining both the total ice concentration and the area covered by multiyear ice. The algorithm utilizes the difference between the horizontally and vertically polarized brightness temperatures to calculate the ice concentration through the use of the polarization parameter, $P R$, defined for each wavelength $\lambda$ by

$$
P R(\lambda)=\frac{T_{B V}(\lambda)-T_{B H}(\lambda)}{T_{B V}(\lambda)+T_{B H}(\lambda)},
$$


where $T_{B H}$ and $T_{B V}$ are the horizontally and vertically polarized brightness temperatures. The polarization, $P R$, for the $1.7 \mathrm{~cm}(18 \mathrm{GHz})$ wavelength is shown in Figure 12a for the entire Arctic. The sharp contrast in $P R$ between ice-free and ice-covered portions of the ocean is clear and demonstrates the utility of $P R$ for calculating sea ice concentration.

The spectral variation with ice type observed in Figure 11 forms the basis for distinguishing between first year and multiyear sea ice in the algorithm. The parameter incorporating these spectral variations at $0.81 \mathrm{~cm}(37 \mathrm{GHz})$ and $1.7 \mathrm{~cm}(18 \mathrm{GHz})$ wavelengths is the spectral gradient ratio, GR, which is defined in terms of the vertically polarized brightness temperatures $T_{B V}$ by

$$
G R=\frac{T_{B V}(0.8)-T_{B V}(1.7)}{T_{B V}(0.8)+T_{B V}(1.7)}
$$

Over the open ocean $G R$ is positive, over first year ice approximately zero, and over multiyear ice negative. As is illustrated in Figure 12b, this parameter varies across the Arctic Basin, indicating the transition from first year ice in the peripheral seas to multiyear ice in the Central Arctic.

The key advantage of using the brightness temperature ratios $P R$ and GR in determining ice concentration and type is that errors due to the unknown thermometric temperature of the ice are greatly reduced. Because microwave brightness temperatures are proportional to thermometric temperature, variations in ice thermometric temperature are a significant source of error in the ice parameter calculations. By using the ratio technique, errors in the calculated ice concentration resulting from unknown horizontal variations in ice temperature across the Arctic are reduced by an order of magnitude compared with algorithms that model the thermometric temperature from climatological data (Cavalieri et al., 1984). The ratio technique, then, reduces the need to acquire independently observed thermometric ice temperatures and to model the physical temperature of the radiating layer of the ice. This radiance ratio technique was utilized to provide the areal percentage of ice cover or ice concentration and the fraction of multiyear ice illustrated in Figure 4 for a five-day period in February 1979.

An alternate approach for utilizing the multichannel SMMR data has been developed by Swift et al. (1984) for operational use in specific regions by the Canadian Atmospheric Environment Service (AES). Essentially, this algorithm is based on a set of linear equations of the form of Eq. 1 in which region-specific microwave emissivities and ice temperatures interpolated from observations are used. The use of both active and passive microwave data for ice type discrimination has also been examined in Canada. The 


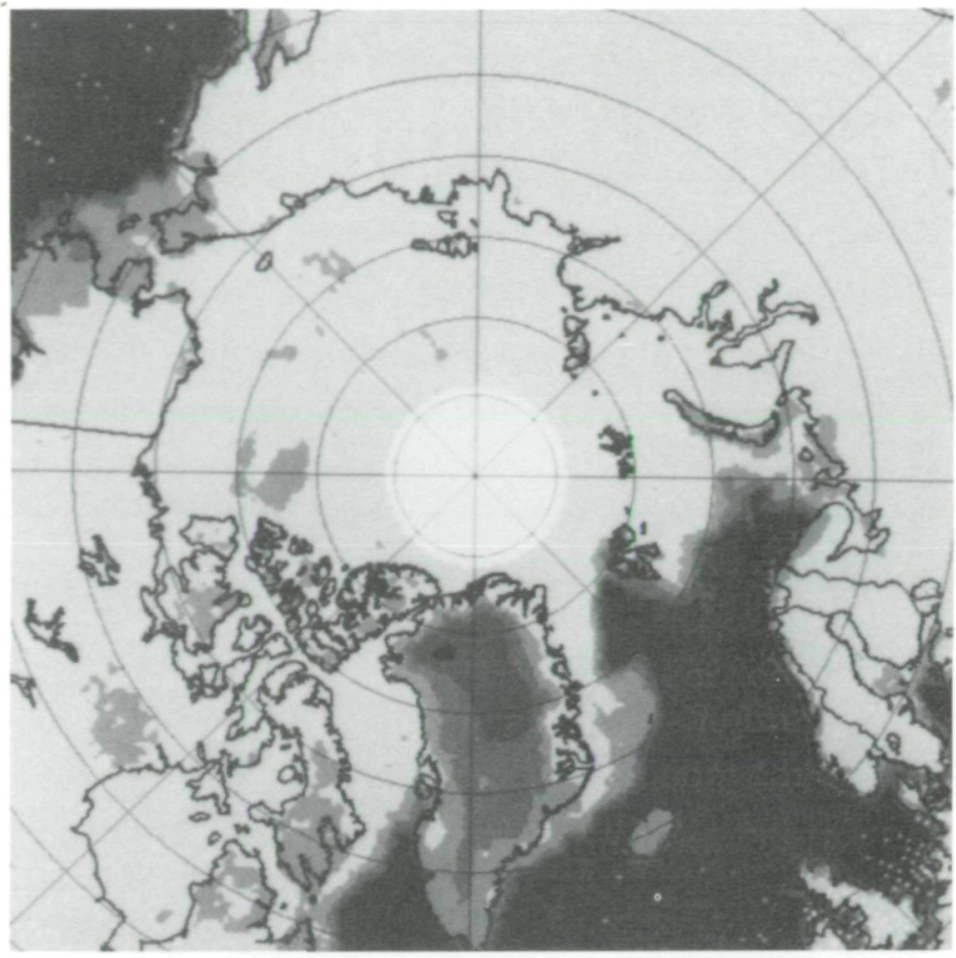

(a)

POLARIZATION

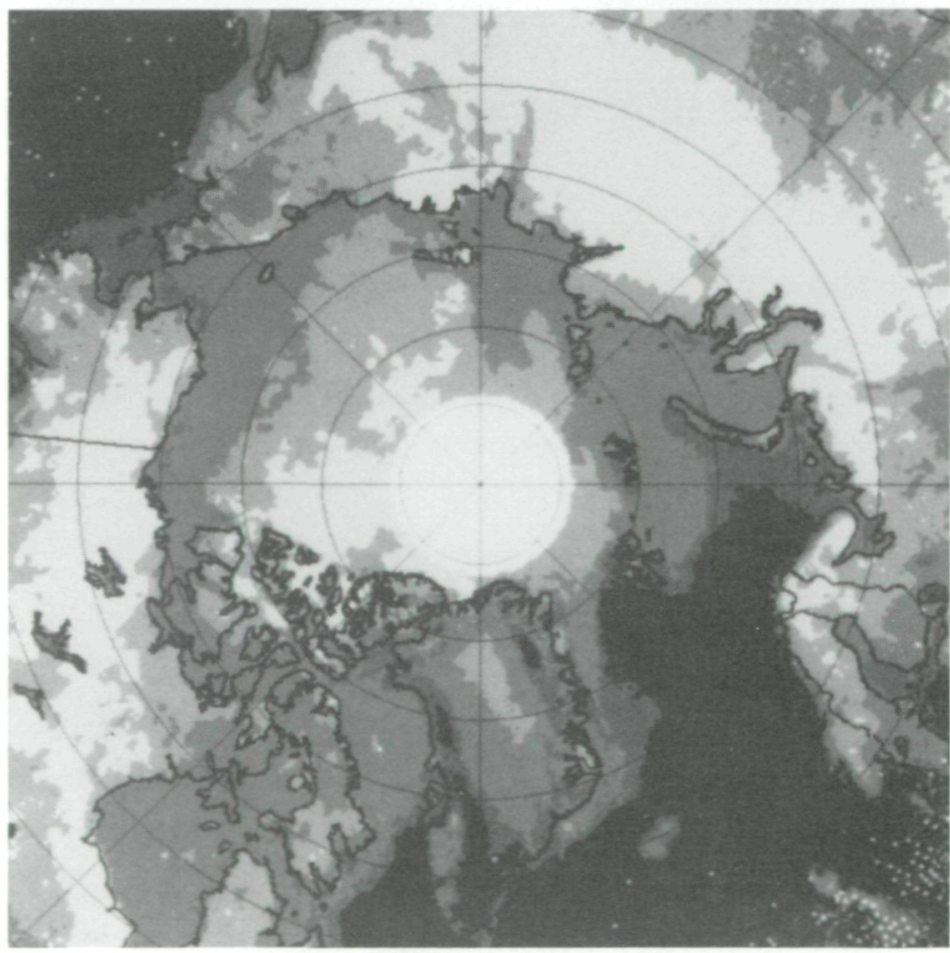

(b)

SPECTRAL GRADIENT

RATIO

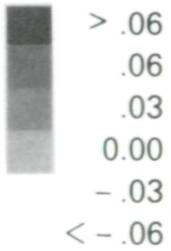

Figure 12. Polar images of (a) the $1.7 \mathrm{~cm}$ wavelength polarization (PR) and (b) the spectral gradient ratio (GR), both computed from Nimbus-7 SMMR data for February 3-7, 1979. The contrast in the polarization between ice-free ocean and consolidated pack ice and the almost uniform polarization across the Arctic Basin shown in (a) demonstrate the utility of using this parameter for calculating ice concentrations. The variation in the spectral gradient ratio across the Arctic Basin shown in (b) illustrates the utility of multispectral information for distinguishing between first year and multiyear ice. 
results of Gray et al. (1982) show great promise in resolving ice type using 13.3 $\mathrm{GHz}$ radar and $19.4 \mathrm{GHz}$ radiometry.

One algorithm designed for operational use with the SMM/I radiance data employs the difference between the horizontal and vertical radiances at $37 \mathrm{GHz}$ for computing ice concentration (Hollinger and Lo, 1983). This approach is similar to the SMMR processing algorithm (Cavalieri et al., 1984) in that it uses the polarization information to obtain ice concentration. Ice type, first year or multiyear, is determined by first calculating a parameter $\mathrm{P}$ derived from the vertically polarized $0.81 \mathrm{~cm}(37 \mathrm{GHz}$ ) wavelength $\mathrm{SSM} / \mathrm{I}$ channel and then comparing $\mathrm{P}$ to a predetermined value $P_{0}$ as follows:

First year ice if $P>P_{0}$

Multiyear ice if $P<P_{0}$.

This method does not allow for mixtures of ice types, but is essentially a first year/multiyear discriminator. The coefficients used in this algorithm are different for each season. At present, except for determining the position of the ice edge, there are no plans for using the $85.5 \mathrm{GHz}$ radiances to retrieve sea ice parameters. Current studies and recent field experiments, however, suggest that use of higher frequency radiances may improve discrimination of ice concentration and ice type (Troy et al., 1981; Grenfell, 1984).

\subsection{Observations in the Marginal Ice Zone (MIZ)}

In marginal ice zones, conditions are sufficiently different to require special techniques for obtaining estimates of ice characteristics. An analysis of the SMMR microwave polarization characteristics observed over the Arctic Basin showed little difference in the horizontally and vertically polarized brightness temperatures (Cavalieri et al., 1984) - in contrast to microwave signatures of sea ice obtained in the Fram Strait region during the Norwegian Remote Sensing Experiment (NORSEX) which showed a significantly greater variance in the horizontal radiances than in the vertical ones (Svendsen et al., 1983). This anomalous behavior of the horizontal polarization is explained by the presence of layers of solid ice in the dry snow covering the sea ice floes in the MIZ. This is probably the result of alternate thawing and freezing cycles which are encountered more frequently in MIZ's than in the Central Arctic. Because of this behavior, the NORSEX group developed a sea ice algorithm that utilized only the vertically polarized SMMR radiances (Svendsen et al., 1983).

Recent analysis of SMMR observations made during the Bering Sea Marginal Ice Zone Experiment (MIZEX-West) shows that the microwave character of 
the ice cover is also influenced by the presence of new ice, young ice, and thin first year ice (MIZEX West Study Group, 1983). SMMR brightness temperatures at the 0.81 wavelength $(37 \mathrm{GHz})$ observed over the entire Bering Sea region are plotted in Figure 13a. Each point is graphed according to the difference and sum of the vertical and horizontal polarizations. This approach results in two distinct clusters: a fairly tight cluster in the upper left corner corresponding to open ocean, and an elongated cluster in the lower right corresponding to sea ice. Using aerial ice reconnaissance data, Cavalieri (1984) found that the $0.81 \mathrm{~cm}(37 \mathrm{GHz})$ SMMR dual-polarized radiances could be used to distinguish among new, young, and first year ice and derive ice concentrations, as indicated in Figure 13b. These results hold promise for using polarization information at this wavelength for subdividing different types of first year ice.

Figure 13a.

Plot of the difference versus the sum of the horizontally and vertically polarized Nimbus-7 SMMR brightness temperatures at the $0.81 \mathrm{~cm}$ wavelength for the entire Bering Sea region. Each point corresponds approximately to one $30 \mathrm{~km}$ SMMR field of view. of the two clusters, which correspond to ice-free ocean and sea ice, the ice cluster is elongated because of the presence of new $(N)$, young $(Y)$, and first year (F) sea ice types. [Cavalieri, 1984]

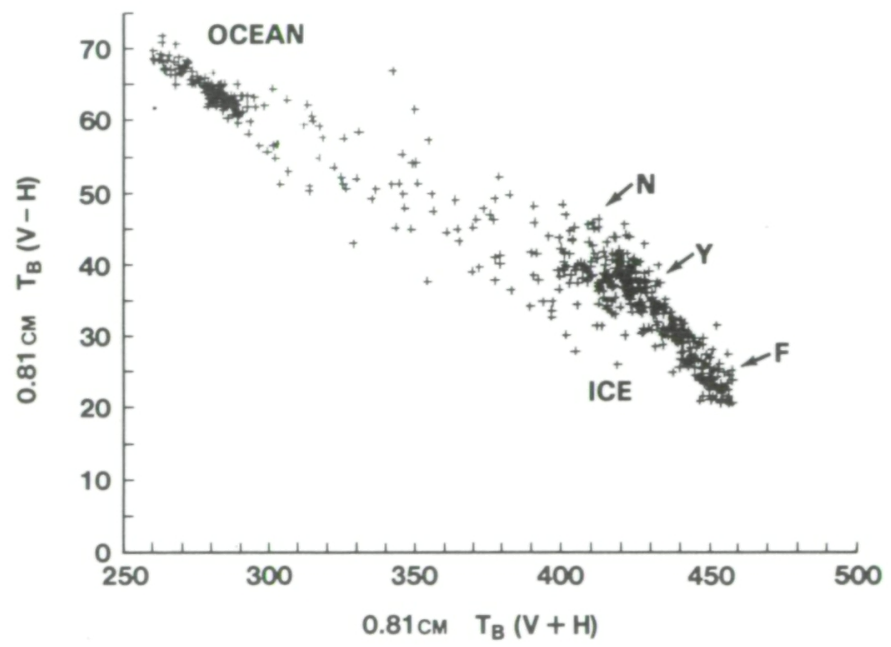

\subsection{Multispectral Cluster Analysis}

There are two radiometrically distinct ice types: saline first year ice and desalinated multiyear ice. Because of the difference in salinity (and therefore in the absorption coefficient), first year ice is substantially more opaque than multiyear ice. Thus for first year ice the observed radiation emanates from a thin layer of ice at the snow/ice interface, whereas multiyear ice radiates from farther below the surface. If effects of the snow cover or the surface, which will be discussed later, are neglected, the emissivity of first year ice is expected to be high and frequency-independent. Multiyear ice, on the other hand, contains inhomogeneities that suppress outgoing radiation 


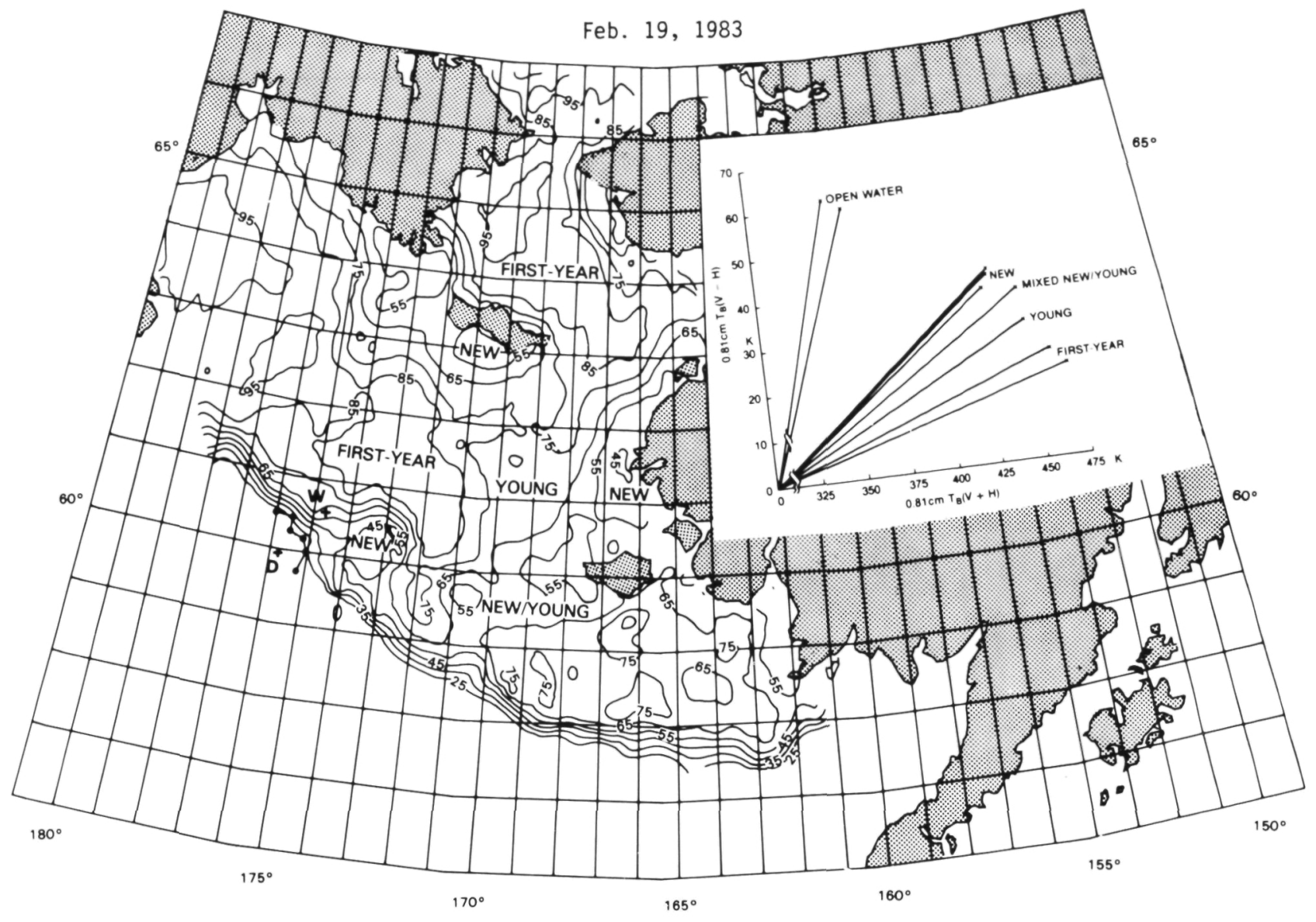

Figure 13b. Bering Sea ice concentration contours derived from the $0.81 \mathrm{~cm}$ wavelength channels of the Nimbus-7 SMMR data for February 19 , 1983. Aerial ice reconnaissance observations made from the NASA CV-990 aircraft coordinated with Nimbus-7 SMMR observations during $M I Z E X$-West demonstrate the discrimination of ice type with the $0.81 \mathrm{~cm}$ wavelength polarization. [after MIZEX-West Study Group, 1983]

because of scattering. The shorter the wavelength, the more scattering will occur, and the more the radiation from deeper layers will be suppressed.

To illustrate how this frequency dependence could be utilized in distinguishing various types (or surfaces) of ice, Figure 14 (left) shows a scatter plot of observed emissivities from the Central Arctic, Chukchi Sea, and Bering Sea region at 37 and $18 \mathrm{GHz}$, in vertical polarization. Also shown (right) are the geographic origin of the points in the scatter plot. Four clusters are identifiable and have been labeled as multiyear ice, first year ice, new ice, and ocean, because the data points originate from the Central Arctic (a region of old floes), the Chukchi Sea (a region of first year ice), the Bering 

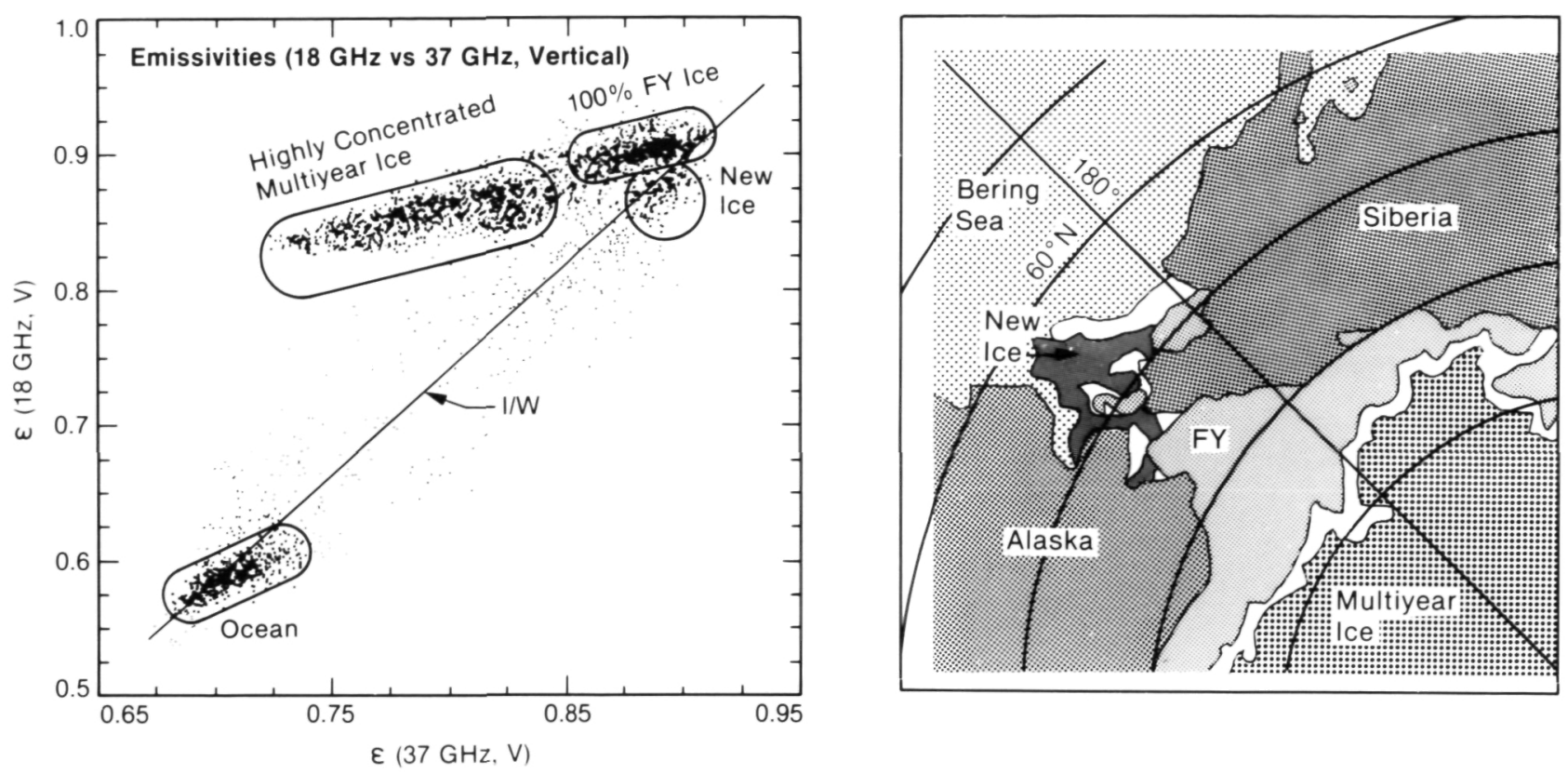

Figure 14. Regional variation of emissivity. Nimbus SMMR and infrared radiometer data are used to generate a scatter plot of emissivities at $37 \mathrm{GHz}$ versus those at $18 \mathrm{GHz}$, vertical polarization, from a rectangular area in the Bering Sea-Chukchi Sea-Arctic Ocean region. The clusters (left) represent highly concentrated multiyear ice, first year ice, new ice, and ice free ocean. The map (right) shows the geographic origin of the cluster data points. [from Comiso, 1983]

Sea (where substantial new ice can be found), and the ice free ocean. The distinct clusters for multiyear and first year ice illustrate the effect of volume scattering discussed in the previous paragraph. The larger spread in the emissivities at $37 \mathrm{GHz}$ than at $18 \mathrm{GHz}$ indicates the greater effect of volume scattering at the shorter wavelength. The identification of the "new ice" cluster also illustrates how the different penetration depths at different frequencies can be utilized. Below a certain threshold thickness, the radiation observed at $37 \mathrm{GHz}$ comes mainly from the ice, whereas that observed at $18 \mathrm{GHz}$ comes partly from the ice and partly from the water underneath the ice. Thus, the emissivity of "new ice" is the same as that of first year ice for the $37 \mathrm{GHz}$ channel but lower for the $18 \mathrm{GHz}$ channel.

Although different ice types tend to cluster differently, some validation is required to interpret the different clusters properly. For example, the data points in the multiyear ice cluster could actually represent a mixture of partly first year and multiyear ice and partly consolidated second year ice. One procedure that could be used to remove the ambiguity is to analyze smaller regions, one at a time. The scatter plots in Figure 15 for February, 


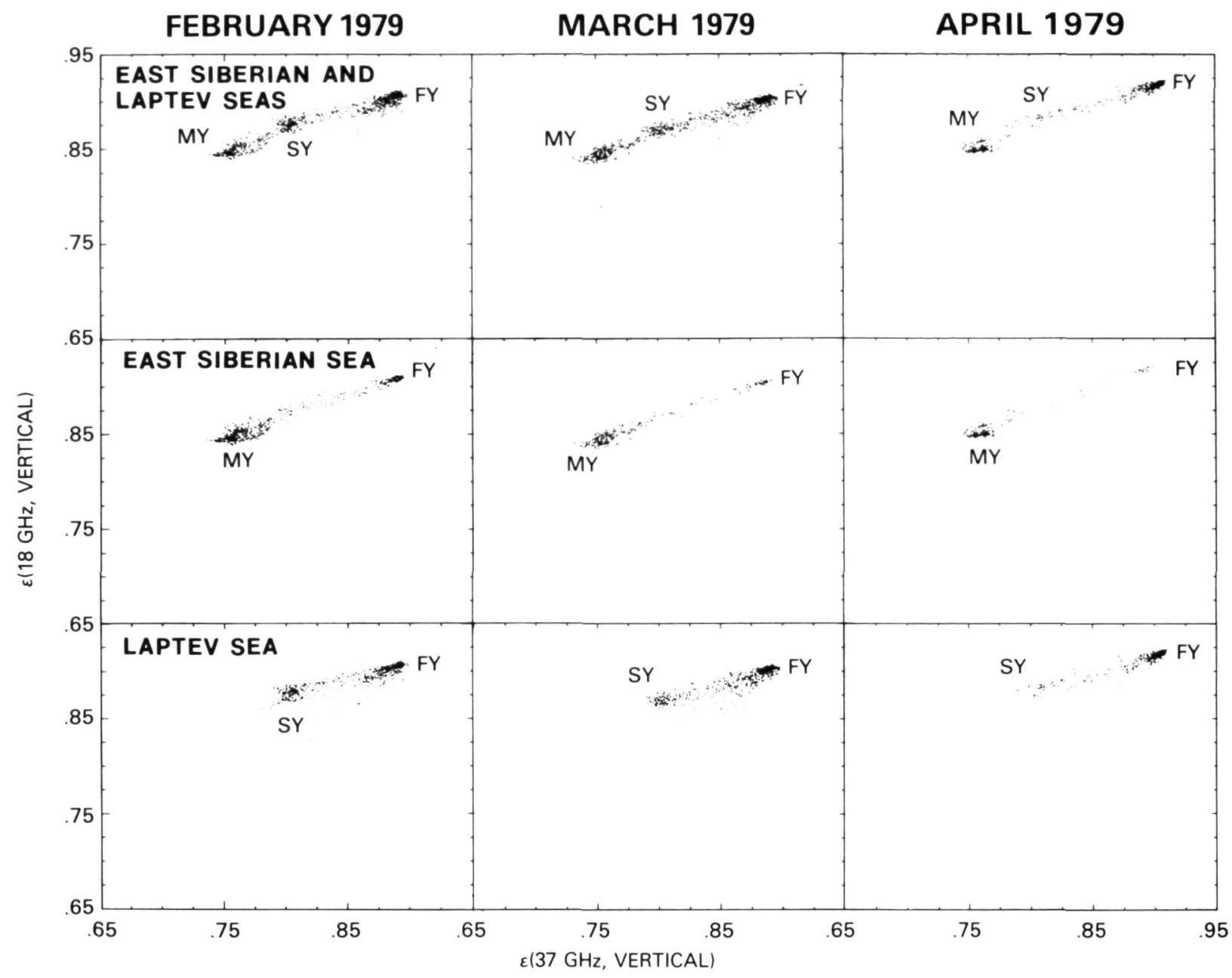

Figure 15. Scatter plot of emissivities at $37 \mathrm{GHz}$ versus those at $18 \mathrm{GHz}$, vertical polarization, from a rectangular area in the East Siberian and Laptev seas during three consecutive uinter months. When the region is subdivided into two sections, the three clusters evident in the top plots split into just two clusters, indicating a large representation of multiyear ice (MY) in the middle plots and possibly of second year ice (SY) in the bottom plots.

March, and April 1979 show how effectively this can be done. In the top row, the combined data points from the East Siberia and Laptev seas consistently form three distinct clusters labeled MY (multiyear), SY (second year) and FY (first year). When the East Siberian Sea and Laptev Sea data are analyzed separately, only two clusters are evident in each case, as shown in the middle and bottom plots. Whereas the SY cluster could not be unambiguously identified in the combined plot, the separate Laptev Sea plot clearly indicates a cluster consistent with the signature measured for second year ice. 
Using these cluster diagrams, we can classify each data point according to ice type by assuming mixing ratios proportional to the distance of that data point to the centroid of each cluster. For a two-cluster case, as in the Laptev Sea and the East Siberian Sea (Figure 15), the proportional amount of first year ice (or multiyear ice) can be derived in a straightforward manner. A similar procedure can be implemented for three nonlinear clusters, such as those shown in Figure 14. The presence of thick or very granular snow cover complicates the problem because it causes an unusually large variability in the emissivity of each ice type, especially at frequencies of $37 \mathrm{GHz}$ or higher. However, a procedure developed by Comiso et al. (1984), which uses two or more frequencies and allows the emissivities to vary, can be used to overcome this problem. The same procedure is also useful in the marginal ice zone, where corrections for atmospheric and other effects are needed to retrieve ice parameters at higher frequencies.

\subsection{Validation}

A satellite is capable of observing vast regions in extremely short times; the radiometer on Nimbus -5 provided a complete map of the area poleward of $55^{\circ} \mathrm{N}$ or $\mathrm{S}$ in 12 hours. The data acquired by the satellite, however, must be interpreted in terms of physical characteristics of the ice cover. Significant progress has been made in achieving this capability. Several algorithms have been compiled to estimate ice concentration and the relative amounts of multiyear and first year ice. The results show broad agreement between different algorithms but some significant differences from in situ data which have not yet been fully explained. A major problem is the lack of "ground truth" information. In situ measurements by observers on the ground are sparse and can only be obtained by great physical effort (Koerner, 1973). Even then, the area that can be covered remains small, and the identification of the type of ice seen by the observer is prone to error.

Passive microwave techniques integrate information from hundreds of square kilometers to provide a composite estimate of average ice conditions within an individual picture element, or "pixel." Accurate validation requires either a detailed knowledge of ice conditions within the pixel area or a knowledge of the statistics of the ice conditions. Broad spatial coverage can be obtained from aircraft, but here the interpretation problem is also present: visual observations are subjective. Nevertheless, airborne measurements offer the greatest promise for testing and improving algorithms used for interpreting satellite data. Aircraft sensors have a high spatial resolution, and individual ice floes can be identified. The ongoing series of MIZEX 
field experiments permits the comparison of in situ measurements by investigators on the ice with simultaneous aircraft observations. This will provide a reliable calibration of data from the airborne sensors. At the same time data from the Nimbus-7 SMMR can be compared with the aircraft measurements.

Another powerful source of validation data is profiles of the ice made by upward-looking sonar from submarines. These give accurate estimates of sea ice draft and its variability. Such profiles cover only a narrow swath, but they do give an estimate of ice type statistics and the amount of open water (Wadhams and Horne, 1980).

At the time of writing this report, an intensive effort is under way to compare results from different algorithms, and to compare all results with available "ground truth" data, including submarine measurements. The purpose of this effort is to compile a "state of the art" algorithm for converting SSM/I data to estimates of sea ice concentration and type (e.g., Hollinger et al., 1984). This algorithm is expected to be more accurate, particularly in determining ice type, than the operational algorithm to be used by the Navy. It is important to establish data processing procedures before SSM/I becomes operational. However, we expect that experience with SSM/I data and acquisition of additional ground truth data will yield improved algorithms. In the next section, we shall review our recommendation for a research program designed to validate and improve SSM/I algorithms and to provide ancillary information that cannot be obtained from SSM/I data. 


\section{Future Research}

We shall consider here two areas of research: work needed to develop and validate algorithms for conversion of passive microwave data to estimates of sea ice characteristics, and acquisition of needed data that cannot be obtained by the SSM/I.

\subsection{Algorithm Improvement and Validation}

Sea ice is constantly changing, both in location and in physical characteristics. Consequently, observing sea ice and validating the observations are difficult tasks. In this situation, it is important to establish a strategy that minimizes the need for the most costly and time-consuming components of the research - in situ measurements. The cluster analysis technique described in Section 3.4 provides the key to our proposed strategy. This technique makes use of the satellite measurements themselves to identify microwave characteristics of the interrogated surface. Limiting values of ice emissivity associated with the clusters can be derived from the data, and geographical locations where these limiting values were measured can be identified. Moreover, changes in brightness temperature clusters over time, together with observed ice drift, can be used to distinguish between changes in the emissivity itself and changes in the composition of the ice cover (ice types).

Clearly, this approach cannot stand alone; there is still need for in situ validation. However, it does serve to identify the locations where, and the seasons when, field efforts will provide a maximum return. We recommend that results from the MIZEX series and more localized work at Mould Bay on Prince Patrick Island in the Beaufort Sea be used to supplement ongoing cluster analysis research. Future field campaigns should be designed primarily to address problems identified by the cluster analysis technique. Such campaigns are extremely costly. They should be planned carefully, and full advantage should be taken of ships of opportunity. We anticipate that this symbiotic approach will result in algorithms for analyzing SSM/I data in terms of all major ice types and of the characteristics of melt pools and snow cover on the ice. These advances will also improve our estimates of ice concentration.

In addition to such field programs, we see a continued need for largescale validation studies. Many of the necessary data will be acquired by existing operations such as the NOAA and DMSP weather satellites, Canadian ice reconnaissance flights, and submarine upward-looking sonar measurements. The Navy/NOAA Joint Ice Center routinely uses many of these data to 
compile assessments of the sea ice cover. This provides an opportunity for systematic comparison of these various data sets with those from SSM/I. We strongly recommend close interaction between the sea ice research community and the Joint Ice Center in order to take full advantage of this opportunity. In addition, we support increased research application of upwardlooking submarine data.

Airborne measurements will continue to be an effective means of obtaining detailed validation data over large areas. In particular, we recommend a series of aircraft validation under-flights after launch of the SSM/I. Planning and timing of these flights should be directed by the prevailing status of sea ice algorithms and by analysis of initial sets of SSM/I data.

\subsection{Ancillary Measurements}

Information that cannot be acquired from SSM/I data includes the following: ice thickness, winds near the ice surface, cloud cover, the state of the ocean beneath the ice, and detailed characteristics of the sea ice such as floe sizes, positions of leads, ridge intensity, and ice velocity. Most of these parameters can be obtained from a combination of other satellite observations, submarine sonar measurements, and data buoys.

\subsubsection{Data buoys}

An array of drifting buoys has been maintained in the Arctic since 1979 (Untersteiner and Thorndike, 1982). At any time, there are approximately 10 buoys giving twice daily measurements of air pressure, buoy temperature, and location. These data provide fields of atmospheric surface pressure (Figure 16) for estimating surface wind fields, temperature, and ice motion.

a. Surface winds. The wind is the primary mechanical force acting on the ice. Measurements taken during the Arctic Ice Dynamics Joint Experiment demonstrated that the surface wind can be estimated accurately from observations of atmospheric pressure made at unmanned data buoys. Surface winds estimated from pressure gradients by extrapolation from coastal stations alone are too inaccurate for calculating ice dynamics.

b. Surface air temperature. At present, temperature is measured inside the drifting buoys. This measurement integrates the effects of air temperature, snow temperature, and radiation in a way that is difficult to interpret. Improvements to the buoys are planned to give a better 

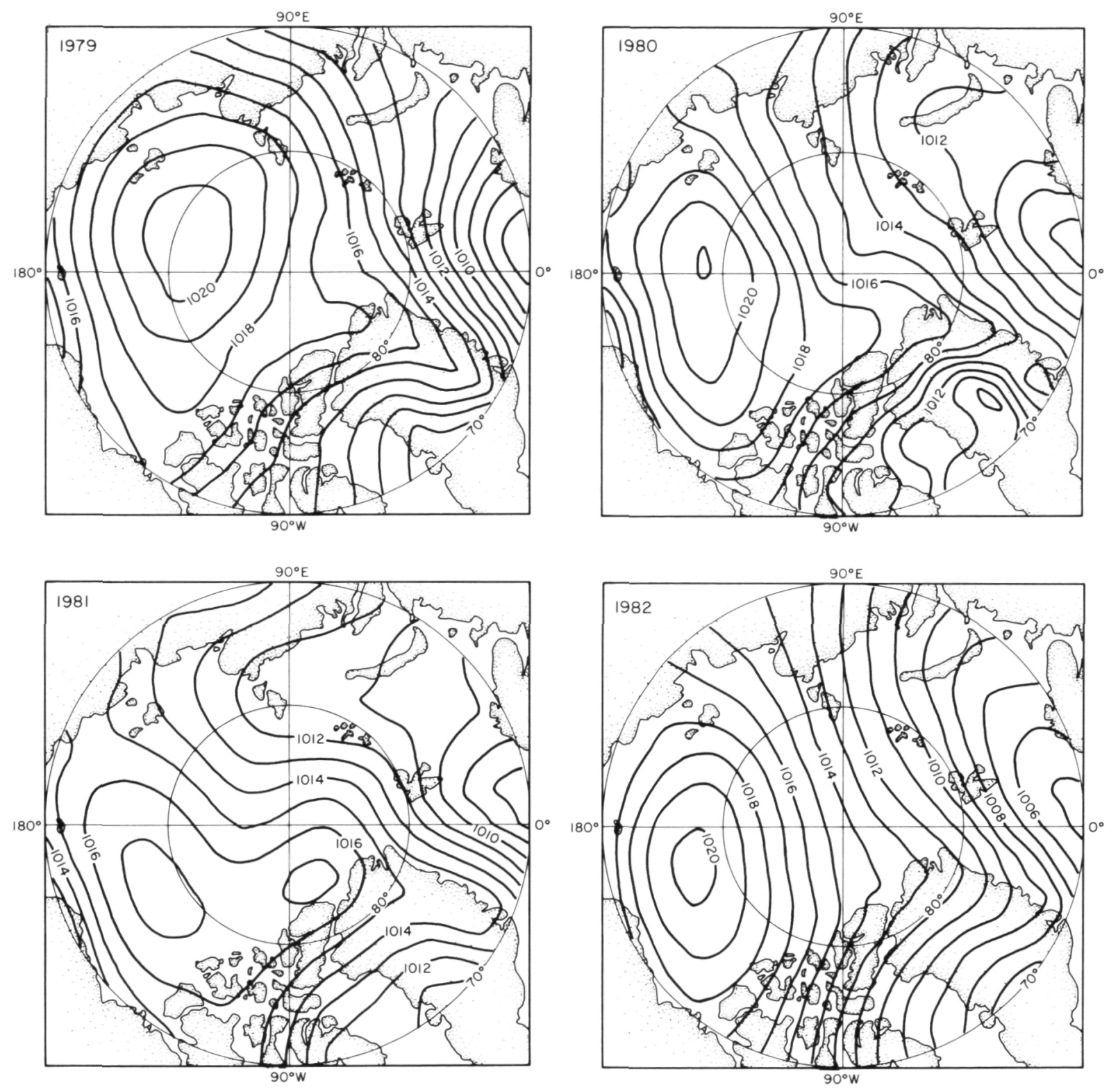

Figure 16. Maps of mean annual atmospheric surface pressure for 1979-1982, indicating a large interannual variability. These maps were calculated from data gathered during the the Arctic Data Buoy Program (Untersteiner and Thorndike, 1982). Started in 1979, this program produces real-time, twice daily maps of surface pressure and ice drift velocity in the Arctic Basin. About 10 drifting data buoys are in operation at any given time. These data have become a crucial tool in driving and validating models of the dynamics of sea ice. Remotely sensed data on ice concentration and ice age (type) along with surface winds and ice displacement derived from data buoys will provide the key to determining the overall ice balance mentioned in Section 1. Efforts are under way to increase the sophistication of the buoys and provide additional data for the calibration of remote sensing instruments. 
measurement of air temperature. This will be of direct value for estimating the heat fluxes between the atmosphere and the ice and for converting measurements of microwave brightness to estimates of surface emissivity.

c. Ice motion. If enough buoys are present, the general field of motion can be resolved (Figure 2 ). From this, the advection and convergence terms in the equations for ice concentration can be derived. Measurements of ice motion are needed to check the output of models of ice dynamics. They can serve also as the driving input to kinematic and dynamic models describing how the ice properties respond to a given velocity field.

We strongly support continuation of the Arctic Buoy Program. We also recommend development of improved buoys capable of measuring temperature profiles within the sea ice and ocean properties beneath the sea ice. These should be used in conjunction with existing types of buoys to provide information on ice growth and melting, stratification of the ocean beneath the ice, sensible heat flux in the oceanic boundary layer (WMO-ICSU, 1984), and other parameters as buoy technology develops. Emplacement of such buoys on antarctic sea ice should have a high priority, since we have negligible information on antarctic sea ice motion and thickness.

\subsubsection{Submarine data}

Upward-looking sonar measurements from submarines have proved to be an invaluable source of data for sea ice thickness distributions (Wadhams, 1981). Although generally limited to a small number of transects across selected regions of the Arctic, the submarine data provide an independent source of information for comparison with passive microwave satellite data. A number of submarine sonar profiles obtained during operation of the Nimbus-5 ESMR (spring, 1976) and of the Nimbus-7 SMMR (spring, 1979; spring and autumn, 1982) provide statistics on amounts of open water and thin ice and on the relative abundance of first year and multiyear ice. Such comparisons of submarine and satellite data will be an important part of the validation effort.

Previous studies of submarine under-ice profiles have demonstrated that there is no large region (30 km or more) that is composed entirely of multiyear ice. Wadhams (1981) found that the percentage of young ice (less than $1 \mathrm{~m}$ thick) in the Central Arctic is usually 1\%-5\%. In addition, there is evidence in the profiles that a measurable quantity of first year ice exists 
throughout the Arctic, mixed with multiyear ice. Figure 17, for instance, shows the probability density function of "level ice" (ice with a local gradient less than 0.025) calculated from a $1400 \mathrm{~km}$ long profile in the Beaufort Sea observed in April 1976. The area under each of the peaks is proportional to the relative abundance of undeformed ice in that thickness class. There are two peaks for young ice representing two preferred drafts (0.3-0.4 $\mathrm{m}$ and 0.8-0.9 m), and the main peak is split into two components, at 2.1-2.2 $\mathrm{m}$ and 2.7-2.8 $\mathrm{m}$. These are interpreted as the preferred drafts of undeformed first year and multiyear ice. The relative areas show that the multiyear ice, while a major component of the ice cover, comprises only about $60 \%$ of the whole.

These results suggest that the microwave radiances used to determine multiyear ice should be interpreted with caution, and that submarine sonar profiles should be analyzed carefully to validate both the multiyear ice fraction and the overall ice concentration calculated by the passive microwave algorithms. The sonar profiles should also yield the maximum fraction of multiyear ice, which should then improve the definition of the multiyear ice radiances. Three submarine data sets (spring 1979, spring 1982, autumn 1982) coinciding with Nimbus-7 SMMR observations are currently being analyzed for this purpose.

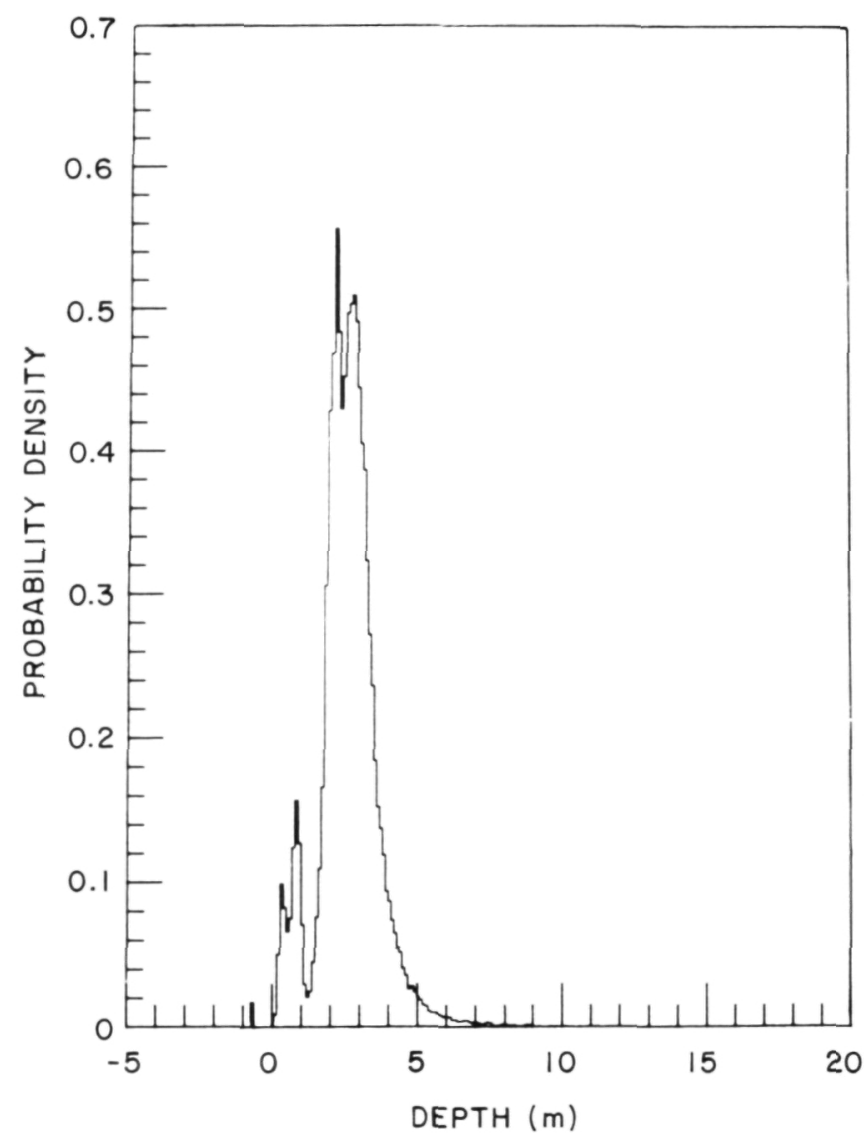

Figure 17.

The draft of sea ice along a $1400 \mathrm{~km}$ track in the Beaufort Sea, obtained by upward-looking sonar from the nuclear submarine Gurnard in April 1976. The probability density distribution shows that the most prevalent ice by far is multiyear ice (see Table 2) with a thickness of 3$4 \mathrm{~m}$. A secondary peak in the spectrum indicates the presence of young and first year ice with a thickness of about $1 \mathrm{~m}$. [from Wadhams and Horne, 1980] 


\subsubsection{Other satellite measurements}

Satellite measurements using sensors other than microwave radiometers also provide important information over the polar regions. Landsat, NOAA, and DMSP weather satellites obtain visible and infrared images which supplement passive microwave data. Reliable data on cloud cover are particularly sparse over the Arctic Ocean (Barry et al., 1984) as a result of problems with discriminating clouds from snow and ice in visible and infrared satellite data. Current sensors and the methods employed by the International Satellite Cloud Climatology Project will not permit mapping of high-latitude cloud amounts and levels. Resolution of this problem on a routine basis must probably await the operational $1.6 \mu \mathrm{m}$ channel sensor planned for a future NOAA polar-orbiting satellite.

Infrared measurements can also be used to calculate ocean and ice surface temperatures. Synthetic aperture radar (SAR) provides images in all weather at a spatial resolution of tens of meters. Comparison of sequential SAR images of the same area gives motion vectors for individual ice floes. Radar altimetry data have been used to detect the margin between ice and ocean, but these data are collected only from directly beneath the satellite. Altimetry data may also provide information on swell within the pack ice and the roughness of the ice surface - a proxy indicator of ice type. Winds over the ice cannot at present be measured from space, but winds seaward of the ice margin can be derived from scatterometer data.

All of these sensors will fly on meteorological or oceanographic satellites for at least part of the time during which the SSM/I will operate aboard DMSP satellites. Important data will be collected, and we strongly recommend that plans for processing and distributing SSM/I data include provisions for distribution of colocated data from these other sensors. 


\section{The Special Sensor Microwave Imager (SSM/I)}

The SSM/I is a microwave radiometer that will be flown aboard a series of satellites operated by the Defense Meteorological Satellite Program starting in late 1985 or 1986. DMSP satellites fly in circular, sun synchronous, nearpolar orbits at an altitude of $833 \mathrm{~km}$ with a period of 101 minutes. The SSM/I is similar to the SMMR deployed on Seasat and Nimbus-7, but with some important differences. The SMMR operates only on alternate days because of spacecraft power limitations, and completes near-global coverage approximately every six days. In one day the SSM/I will give highly redundant coverage of the polar regions (see Figure 18), as well as virtually complete coverage of the equatorial band. The SMMR operates at five frequencies $(6.6,10.69$, $18.0,21.0$, and $37.0 \mathrm{GHz}$ ), each of which has a channel for both vertical and horizontal polarization. The SSM/I will operate at four frequencies (19.35, $22.235,37.0$, and $85.5 \mathrm{GHz}$ ) with two polarizations at each frequency except 22 $\mathrm{GHz}$, which will have only a vertical polarization channel.

\subsection{Description of the Instrument}

The SSM/I consists of an offset parabolic reflector, approximately $60 \times 65 \mathrm{~cm}$ in size, and a seven-port horn antenna mounted on a rotating drum that contains the radiometers, digital data subsystem, mechanical scanning subsystem, and power subsystem. A small mirror, positioned to reflect the cold sky and a "hot" reference of known temperature, provides cold and hot calibration references during each scan. A prototype of the SSM/I in the deployed position is shown in Figure 19.

SSM/I data are organized spatially by pixel, scene station, and scan A pixel is the smallest data element and is a radiometric sample of a single footprint of a single frequency and polarization. A scene station is the center of coaxially located pixels. A scan is one rotation of the drum during which scene station, cold calibration, hot calibration, and housekeeping data are taken.

With a velocity of $6.58 \mathrm{~km} / \mathrm{s}$ the satellite advances approximately $12.5 \mathrm{~km}$ during each $1.9 \mathrm{~s}$ antenna rotation period. Over the active scan angle of $102.4^{\circ}$, which covers a $1394 \mathrm{~km}$ wide swath on the surface, there are 128 scene stations. Alternate scans are labeled "A" and "B." Each A scan contains 64 samples of the five lower frequency channels at $1.6^{\circ}$ intervals and 128 samples of the two $85.5 \mathrm{GHz}$ channels at $0.8^{\circ}$ intervals. Each B scan contains only the 128 samples of the two $85.5 \mathrm{GHz}$ channels. This method results in a scene station spacing, in both directions, of about $25 \mathrm{~km}$ for the five lower 


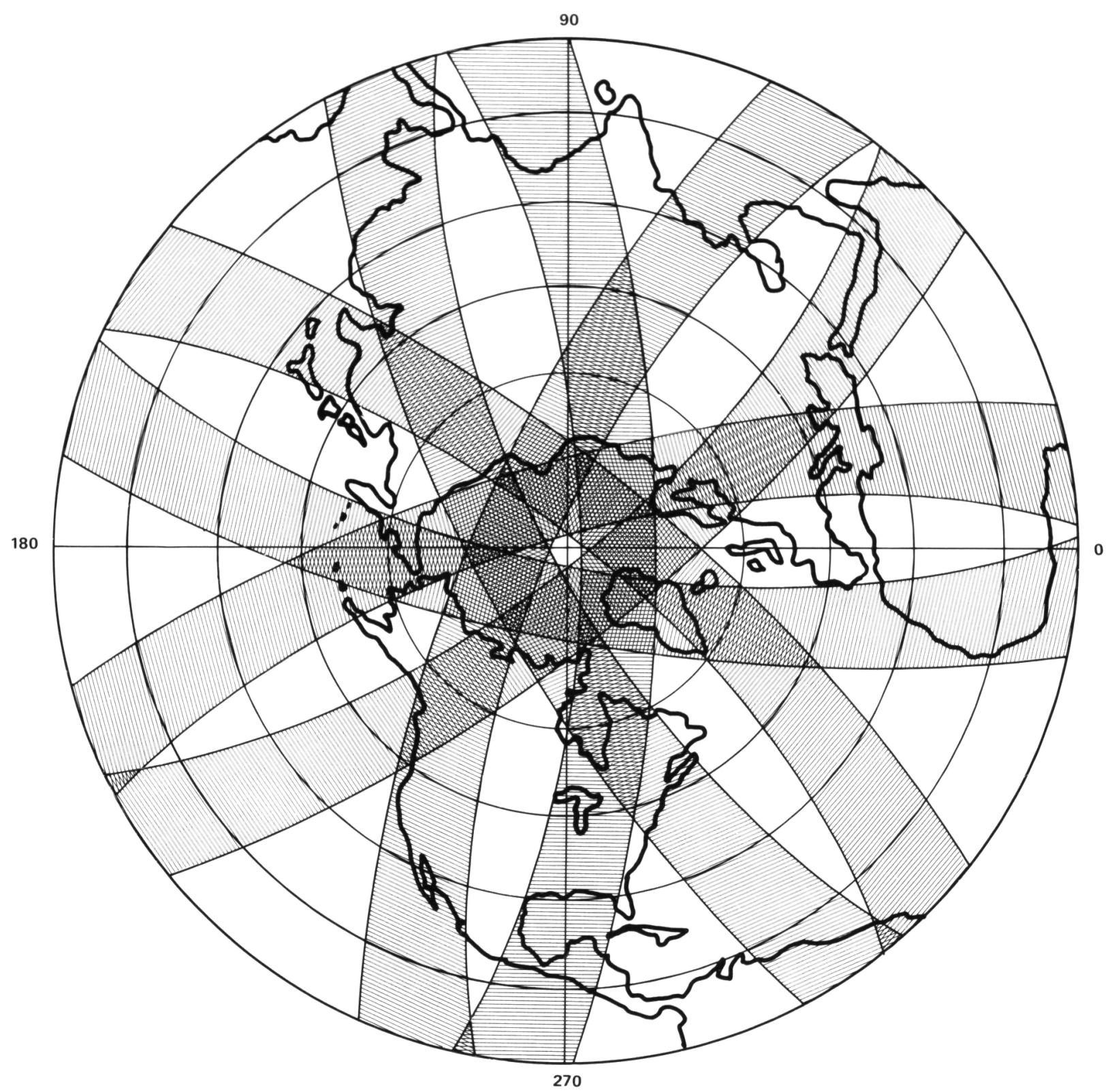

Figure 18. Coverage of the northern hemisphere during one-half day by the DMSP $S S M / I$. The hatched areas show swaths observed by the microwave radiometer during a 12-hour period. In the subsequent 12 hours most of the remainder of the surface, except for some small equatorial areas, would be observed. The small area surrounding the pole is not observed by $S S M / I$. 


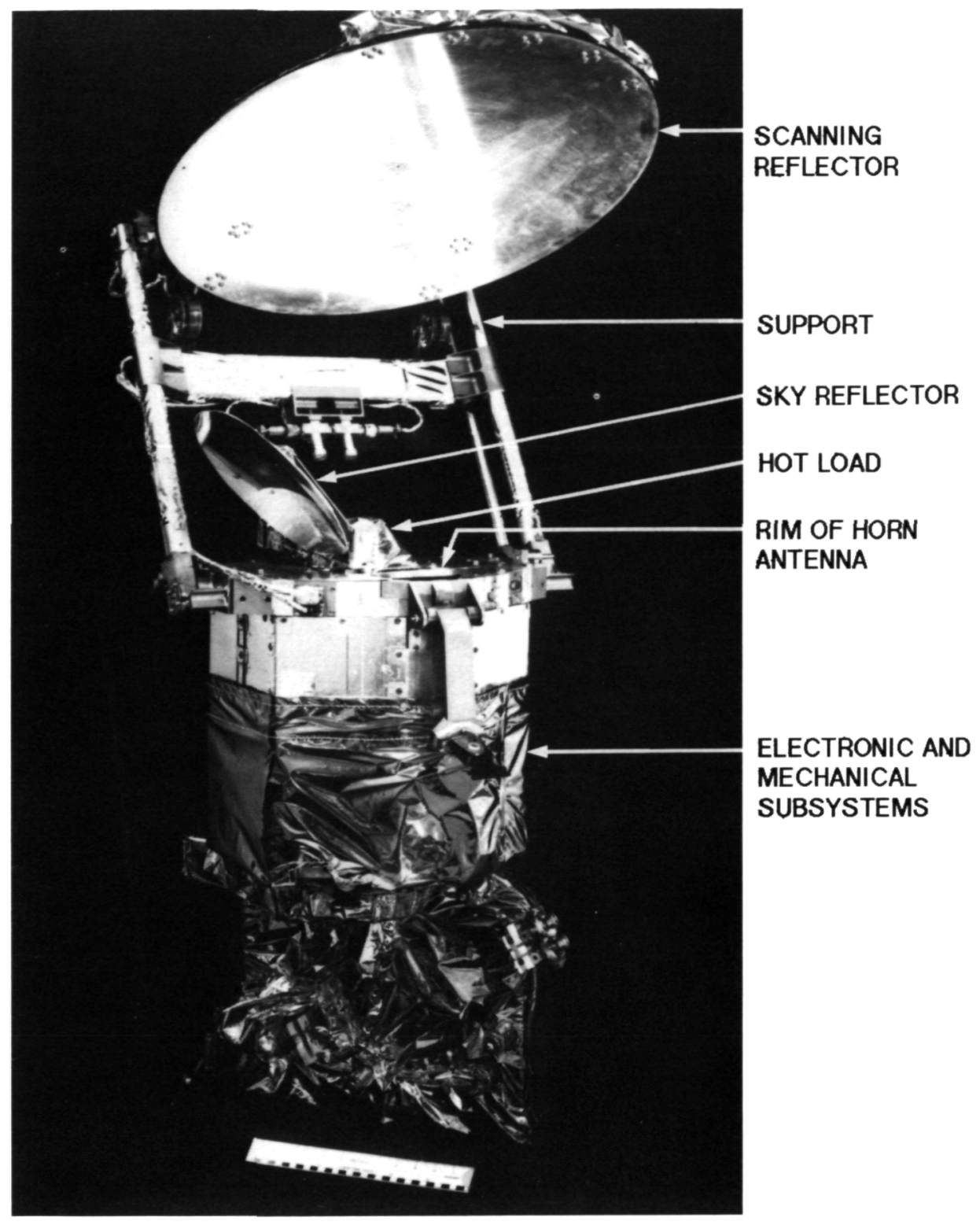

Figure 19. The seven-channel SSM/I radiometer ready for placement aboard a satellite. In this figure, up is also up on the spacecraft, i.e., perpendicular to the earth's surface. The key elements of SSM/I are the scanning reflector, the calibration loads, the horn antenna, and the electronic and mechanical subsystems. The scanning reflector, the large disk-like object at top, and its support framework are rotated. This rotation causes the area "seen" on the surface to be swept in a circular path with the propagation lines forming a large cone. In operation, microwaves from the surface are focused by the reflector into a horn antenna whose rim is just visible near the image center. As the scanning reflector is turned, the small disk called the sky reflector, which is facing to lower left in the figure, is brought before the horn antenna (between it and the scanning reflector) once per revolution and causes the antenna to "see" outer space instead of the earth's surface and thus to obtain a cold, or low constant radiance, calibration point. Further along in the revolution, the antenna is exposed to a "hot load" source of high, known radiance for another calibration point. The hot load is not visible because it is behind the sky reflector. Thus, an absolute calibration including the horn antenna is monitored during each scan. 
frequency channels and $12.5 \mathrm{~km}$ for the two $85.5 \mathrm{GHz}$ channels. Figure 20 shows the scan geometry.

An integration time of $7.95 \mathrm{~ms}$ is used for the lower frequencies whereas $3.89 \mathrm{~ms}$ is used for $85.5 \mathrm{GHz}$. The performance characteristics of the SSM/I are shown in Table 4. Note that in each case the effective beamwidths provide substantial overlap between adjacent pixels.

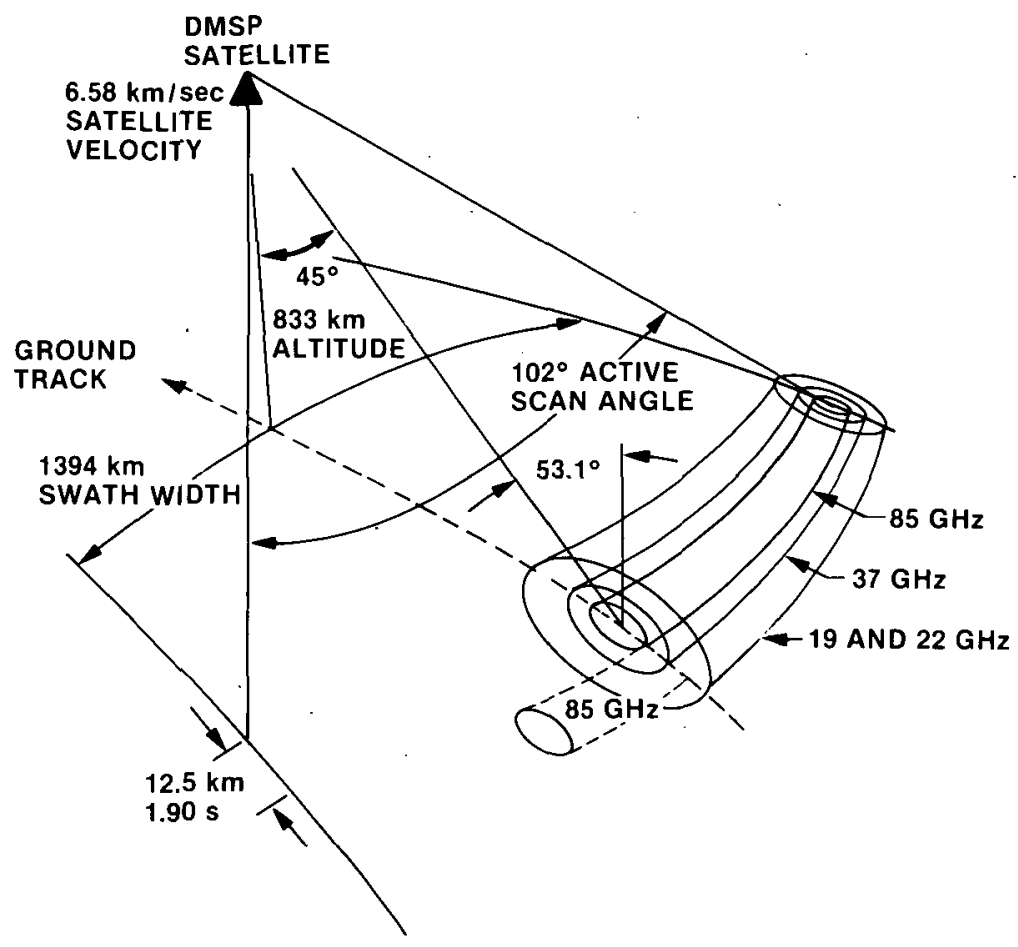

Figure 20.

Scan geometry for SSM/I. The rotating antenna system on $S S M / I$ sweeps the observed area on the surface in two alternating modes, one in which all four frequencies are recorded and one in which only the $85 \mathrm{GHz}$ data are recorded. The angle of emission at the surface is a constant across the swath. The use of a single antenna for all four frequencies results in a different surface resolution for each frequency, with the highest frequency. $85 \mathrm{GHz}$ having the finest resolütion, less than $15 \mathrm{~km}$.

Table 4. SSM/I performance characteristics [from Hollinger and Lo, 1983].

\begin{tabular}{|l|c|c|c|c|}
\hline \multicolumn{1}{|c|}{ Parameter } & \multicolumn{4}{|c|}{ Radiometer Performance } \\
\hline Center Frequency, GHz & $19.35 \pm 0.05$ & $22.235 \pm 0.05$ & $37.0 \pm 0.1$ & $85.5 \pm 0.3$ \\
Polarization & Vert. \& Horz. & Vert. & Vert. \& Horz. & Vert. \& Horz. \\
Radiometric Accuracy, K & 1.5 & 1.5 & 1.5 & 1.5 \\
$\begin{array}{l}\Delta \text { T (noise), K } \\
\text { Dynamic Temp. Range, K }\end{array}$ & 0.8 & 0.8 & 0.6 & 1.1 \\
$\begin{array}{l}\text { Effective Resolution, km } \\
\text { (3 dB antenna beamidth; } \\
\text { includes integ. time) } \\
\text { Integration Time, ms }\end{array}$ & $70 \times 45$ & $60 \times 40$ & 375 & 375 \\
\hline
\end{tabular}




\subsection{Data Products}

The DMSP will transmit SSM/I data to the Telemetry and Data Relay Spacecraft (TDRS) in geosynchronous orbit for relay to a ground station in White Sands, New Mexico. This station will, in turn, relay the data over a domestic communications satellite link to the Fleet Numerical Oceanography Center (FNOC) and to Air Force Global Weather Central (AFGWC).

The raw data stream is packed to be compatible with the sampling strategy of the Optical Linescan System (OLS), the primary sensor aboard DMSP. The OLS accepts one 3276-bit block from the SSM/I every second. These blocks are either transmitted immediately or recorded on board for later playback to a ground station. Once this serial bit stream is recorded on the ground, it is defined as Level $O$ data (see Table 5 for processing level definitions).

Table 5. Processing level definitions.

\begin{tabular}{|c|c|}
\hline Leve1 0 & Raw satellite data \\
\hline Level 1 & Earth located engineering units \\
\hline Level 1.5 & $\begin{array}{l}\text { Temperature Data Records (TDR's) and } \\
\text { Sensor Data Records (SDR's) }\end{array}$ \\
\hline Level 2 & $\begin{array}{l}\text { Navy's Environmental Data Records (EDR's) } \\
\text { in swath format }\end{array}$ \\
\hline Level 3 & $\begin{array}{l}\text { Gridded brightness temperatures and ice } \\
\text { concentration maps (total ice, first year, } \\
\text { multiyear) }\end{array}$ \\
\hline
\end{tabular}

Processing at FNOC and AFGWC will include production in swath format of Sensor Data Records, or SDR's (Level 1.5), Environmental Data Records, or EDR's (Level 2), and, possibly, antenna temperatures (TA's) to be included as Temperature Data Records, or TDR's (Level 1.5). The antenna temperatures are the data from which the SDR's are calculated by correcting for the antenna pattern. The SDR's are earth-located brightness temperatures in degrees Kelvin that have been tagged for surface type, calibrated, corrected for antenna pattern, formatted, and written to a file for later processing. 
The EDR's are geophysical parameters computed from the SDR's using operational algorithms. NESDIS Satellite Data Services Division (NESDIS/SDSD) will archive TDR's, SDR's, and EDR's.

The Working Group considers the operational algorithms inadequate for research applications. To meet research needs, we recommend computation and archival of sea ice extent, concentration, and type using algorithms currently under development.

\subsection{Radiometer Performance Checks}

Spacecraft sensors tend to undergo long-term changes in sensitivity, usually in the form of a degradation. Consequently, the calibration of SSM/I should be routinely validated by examining, at least monthly, the brightness temperatures of certain monitor areas, regions of the earth a few hundred kilometers across, known to have only a small variation in microwave emission over long periods (see Table 6). Examples of such regions are the

Table 6. Summary of data sets recommended for archival.

\begin{tabular}{|c|c|c|c|c|}
\hline Data Set & $\begin{array}{c}\text { Time Average } \\
\text { (days) }\end{array}$ & $\begin{array}{c}\text { Channels } \\
(\mathrm{GHz})\end{array}$ & Parameters & $\begin{array}{c}\text { Storage } \\
\text { (MBytes/year) }\end{array}$ \\
\hline SDR's & N/A (swath) & $\begin{array}{l}19.4 \mathrm{~V}, \mathrm{H} \\
22.2 \mathrm{~V} \\
37.0 \mathrm{~V}, \mathrm{H} \\
85.5 \mathrm{~V}, \mathrm{H}\end{array}$ & $\begin{array}{l}\text { Global } \\
\text { brightness temperatures } \\
\text { in swath format }\end{array}$ & 28,000 \\
\hline $\begin{array}{l}12.5 \mathrm{~km} \\
\text { brightness } \\
\text { temperatures }\end{array}$ & 1 & $85.5 \mathrm{~V}, \mathrm{H}$ & $\begin{array}{l}\text { Gridded average } \\
\text { brightness temperatures } \\
\text { (polar regions on } 1 \text { ) }\end{array}$ & 2,150 \\
\hline $\begin{array}{l}25 \mathrm{~km} \\
\text { brightness } \\
\text { temperatures }\end{array}$ & 1 & $\begin{array}{l}19.4 \mathrm{~V}, \mathrm{H} \\
22.2 \mathrm{~V} \\
37.0 \mathrm{~V}, \mathrm{H}\end{array}$ & $\begin{array}{l}\text { Gridded average } \\
\text { brightness temperatures } \\
\text { (polar regions on } 1 \text { y) }\end{array}$ & 1,350 \\
\hline $\begin{array}{l}50 \mathrm{~km} \\
\text { ice maps }\end{array}$ & 3 & Combination $^{a}$ & $\begin{array}{l}\text { Gridded average total } \\
\text { ice concentration and } \\
\text { multiyear ice fraction } \\
\text { (polar regions only) }\end{array}$ & 240 \\
\hline Ice extent & 1 & $85.5 \mathrm{~V}, \mathrm{H}^{\mathrm{a}}$ & Ice boundary & 2 \\
\hline Monitor areas & 1 & $\begin{array}{l}19.4 \mathrm{~V}, \mathrm{H} \\
22.2 \mathrm{~V} \\
37.0 \mathrm{~V}, \mathrm{H} \\
85.5 \mathrm{~V}, \mathrm{H}\end{array}$ & $\begin{array}{l}\text { Summary of brightness } \\
\text { temperatures in moni- } \\
\text { tor areas }\end{array}$ & 0.6 \\
\hline
\end{tabular}

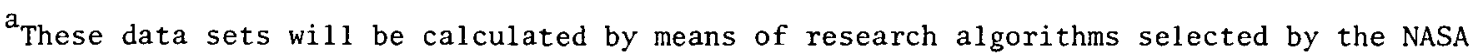
Sea-Ice Algorithm Working Group. The combination of channels to be used in the algorithms has not yet beeen specified. 
Southeast Pacific, the Amazon rain forest, and the antarctic ice sheet. By using the measured brightness temperatures of these features, and by linearly adapting SSM/I SDR radiances to keep these values constant, consistent brightness temperatures should be provided to the algorithms used to generate geophysical parameters for research purposes.

\subsection{Earth Location}

It is crucial to know precisely the location of each of the scene stations. The required accuracy is one-third the size of the finest resolution pixel. In the case of SSM/I, the $85 \mathrm{GHz}$ data have a spatial resolution of $14.5 \mathrm{~km}$, which implies the earth location must be accurate to within $5 \mathrm{~km}$. It is expected that the SDR's earth location accuracy should satisfy this requirement, based on the reported system specifications. However, routine checks should be made to ensure this accuracy is maintained. 


\section{Data Products for Research}

The data products required are determined by the time and space scales at which the sea ice cover responds to its environment. The inherent scale of sea ice microwave variation is a few days during periods of ice-edge advance and retreat and surface melting; it is about one day along the ice margin. Spatial scales in the margins are tens of kilometers. These scales call for daily data at a resolution of $10-20 \mathrm{~km}$.

The SSM/I data set will be of sufficiently fine spatial and temporal resolution to permit mapping of the polar regions on a daily basis. The appropriate daily data base should contain brightness temperatures for all channels, earth-gridded and binned, with two computed geophysical parameters: ice concentration and ice type. The recommended ice products are summarized in Table 6.

The geographical areas that should be covered are illustrated in Figure 21. The northern area includes the North American Great Lakes and the Sea of Okhosk, and the southern area includes the maximum extent of Southern Ocean sea ice.

Because the brightness temperature data base covers several years and is expected to be useful beyond the lifetime of the sensor, it is important to place the scientific archive on media that are highly reliable, long lived, and easily accessible. These requirements preclude the use of magnetic tape as a primary storage medium. Experience has shown that tape degrades with time, requires periodic exercising, and is time consuming to handle. A far better solution would be digital optical storage disks. This method fulfills all the archival requirements, with the added advantage of being less expensive than any of the magnetic media alternatives now available.

\subsection{Data Archives and Access}

In addition to the basic archival services provided by NESDIS/SDSD, the Working Group endorses development of capabilities for providing high-level ice products by the Pilot Ocean Data System (PODS) at the Jet Propulsion Laboratory (Table 6) and the planned transfer of these capabilities to the National Snow and Ice Data Center (NSIDC) at the University of Colorado after the launch of SSM/I.

These archives are intended principally for scientists performing retrospective analyses of sea ice and snow phenomena. Access will be provided by a "menu-driven," on-line system that allows browsing and catalog review. The research data sets selected will be written on magnetic tape or optical disk 

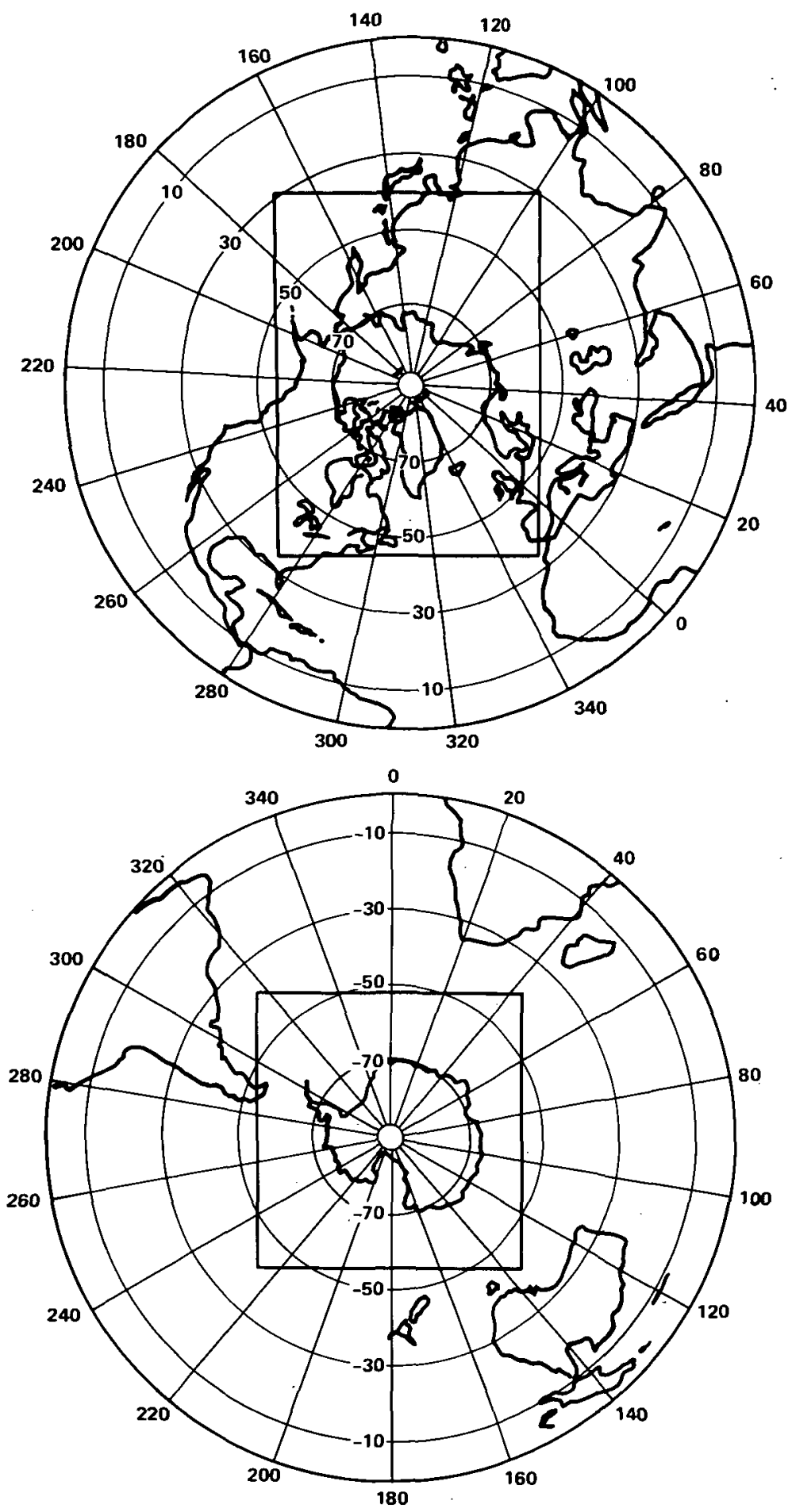

Figure 21. Geographical areas in the northern and southern hemispheres to be covered by the PODS archive of $S S M / I$ data, which will include microwave brightness, ice concentration, and ice type. These data, originally acquired in spacecraft orbital coordinates, will be converted to terrestrial geographical coordinates. 
and delivered to the user by mail. Thus the time between selection and receipt of data can, if necessary, be as short as one week.

If real-time data are needed, for instance, in support of field activities, such data will be available from the Navy-NOAA Joint Ice Center.

\subsection{Algorithm Selection}

Geophysical algorithms are still in a state of development. Therefore, the Science Working Group recommends that algorithm research be vigorously pursued, including the development of validation methods: NASA is currently sponsoring research to develop an optimal set of algorithms to fulfill our recommendations, and we expect that this set will be available by the time of launch. We recommend that this activity be followed by suitable studies toward validating the algorithms used. 


\section{Conclusion}

Interactions of the atmosphere and ocean in high latitudes are an essential component of the global climate system. This interaction is strongly affected by the presence of ice floating on the sea surface. A key problem in developing an understanding of air-sea-ice interaction has been lack of suitable observations on the appropriate time and space scales in the remote and inhospitable polar regions. Over the past decade earth observing satellites carrying microwave sensors have demonstrated a unique all-weather capability to acquire sea-ice data year round. Microwave data sets provide routine global mapping of ice extent, concentration, and type. The data to be acquired from the Special Sensor Microwave Imager (SSM/I) aboard Defense Meteorological Satellite Program spacecraft will extend the already substantial time series of ice observations from past satellite missions and greatly enhance the value of existing data.

Exploitation of SSM/I data for sea-ice research involves the following steps:

a. An archive of both observed brightness temperatures and derived geophysical parameters must be maintained to provide data of optimal utility for the research community.

b. Continued research is needed to refine the methods for deriving geophysical data from the microwave record. This research includes simultaneous in situ studies of ice conditions and microwave behavior, and analysis of the historical data set.

c. Investigations of polar ice, ocean, and atmosphere interactions should include acquisition and analysis of in situ data from buoys, surface ships, and submarines, as well as modeling studies.

The Science Working Group strongly recommends that a capability to process, archive, and access the SSM/I data be developed by the Pilot Ocean Data System at the Jet Propulsion Laboratory. Furthermore, we recommend that the SSM/I data base be housed at the National Snow and Ice Data Center in Boulder. The archive should contain microwave brightness temperatures and geophysical parameters derived from these brightness temperatures. These data should be archived in swath format, and averaged to provide gridded or mapped products. We recommend creation and operation of an archive containing the following data:

a. Global swath brightness temperature data for all seven channels of the SSM/I. 
b. Daily averaged microwave brightness temperatures at $25 \mathrm{~km}$ resolution for the five lower-frequency channels and at $12.5 \mathrm{~km}$ resolution for the $85 \mathrm{GHz}$ channels.

c. Three-day averaged estimates of ice concentration and multiyear ice fraction on a $50 \mathrm{~km}$ grid.

d. Daily ice-edge maps on a $12.5 \mathrm{~km}$ grid.

e. Daily brightness temperatures over selected areas with little seasonal change. These data will be used to monitor long-term sensor performance.

Satellite data can be used to gain a fuller understanding of processes such as air-sea-ice interactions only in the context of a total research program that includes in situ observations, modeling, and process studies. The value of these programs depends on suitable methods for integrating their diverse output products and initial assumptions. This is the area in which the recommended data archive system, optimized for efficient access, plays the greatest role. The development and maintenance of an archive for SSM/I data is the central recommendation of this document. Through the archive, the satellite observations and the research activities of all scientists will enhance progress in describing air-sea-ice interactions and their effects on the ocean-atmosphere system. .

Because geophysical algorithms remain in a state of development, the Science Working Group recommends that algorithm research be vigorously pursued. NASA is currently sponsoring research to develop an optimal set of algorithms to fulfill the recommendations made here, and we expect that this set will be available by the time of launch. We recommend that this activity be followed by an algorithm validation effort comprising focused field experiments, supplemented by data from submarines, buoys, and airborne surveys. These data are needed both to validate the satellite measurements and to complement them by providing information that cannot be acquired from space. 


\section{References}

Ackley, S.F., and T.E. Keliher, 1976: Antarctic sea ice dynamics and its possible climatic effects. AIDJEX Bull., 33, 53-76.

Barry, R.G., A. Henderson-Sellers, and K.P. Shine, 1984: Climate sensitivity and the marginal cryosphere. Climate Process and Climate Sensitivity. Eds. J. Hansen and T. Takahashi, Geophys. Monogr., 25, American Geophys. Union, pp. 21-237.

Budd, W.F., 1975: Antarctic sea-ice variations from satellite sensing in relation to climate. J. Glaciol., 15, 417-427.

Carsey, F.D., 1980: Microwave observation of the Weddell polynya. Mon. Weather Rev., 108, 2032-2044.

Carsey, F.D., 1982: Arctic sea ice distribution at end of summer 1973-1976 from satellite microwave data. J. Geophys. Res., 87, 5809-5835.

Carsey, F.D., 1984: Summer arctic sea ice character from satellite microwave data. J. Geophys. Res., in press.

Cavalieri, D.J., 1984: personal communication.

Cavalieri, D.J., and C.L. Parkinson, 1981: Large-scale variation in observed Antarctic sea ice extent and associated atmospheric circulation. Mon. Weather Rev., 109, 2323-2336.

Cavalieri, D.J., S. Martin, and P. Gloersen, 1983: Nimbus 7 SMMR observations of the Bering Sea ice cover during March 1979. J. Geophys. Res., 88, 2743-2754.

Cavalieri, D.J., P. Gloersen, and W.J. Campbell, 1984: Determination of sea ice parameters with the Nimbus 7 SMMR. J. Geophys. Res., 89, 5355-5369.'

Colony, R., and A.S. Thorndike, 1984: An estimate of the mean field of arctic sea ice motion: J. Geophys. Res., 89, 10623-10629.

Comiso, J.C., 1983: Sea ice effective microwave emissivities from satellite passive microwave and infrared observations. J. Geophys. Res., 88, 7686-7704.

Comiso, J.C., and H.J. Zwally, 1982: Antarctic sea ice concentrations inferred from Nimbus 5 ESMR and Landsat imagery. J. Geophys. Res., 87, 5836-5844.

Comiso, J.C., S.F. Ackley, and A.L. Gordon, 1984: Antarctic sea ice signatures and their correlation with in situ ice observations. J. Geophys. Res., 89, 662-672.

Cox, G.F.N., and W.F. Weeks, 1974: Salinity variations in sea ice. J. Glaciol., 13, $109-120$.

Fu, L.-L., and B. Holt, 1982: Seasat Views Oceans and Sea Ice with Synthetic Aperture Radar. Jet Propulsion Laboratory, Pasadena, 200 pp. 
GARP (WMO-ICSU), 1975. The Physical Basis of Climate and Climate Model ling. GARP Publ. Ser. No. 16, Global Atmospheric Research Program, Geneva, 265 pp.

GARP (WMO-ICSU), 1979: The Polar Sub-Programme. GARP Publ. Ser. No. 19, Global Atmospheric Research Program, Geneva, 47 pp.

Gloersen, P., T.T. Wilheit, A.T.C. Chang, W. Nordberg, and W.J.Campbell, 1974: Microwave maps of the polar ice of the earth. Bull. Am. Met. Soc., 55, 1442-1448.

Gloersen, P., H.J. Zwally, A.T.C. Chang, D.K. Hall, W.J. Campbell; and R.O. Ramseier, 1978: Time-dependence of sea ice concentration and multiyear ice fraction in the Arctic Basin. Boundary Layer Met., 13, 339-359.

Gordon, A.L., 1978: Deep Antarctic convection of Maud Rise. J. Phys. Oceanogr., 8, 600-612.

Gordon, A.L., 1981: Seasonality of southern ocean sea ice. J. Geophys. Res., B6, 4193-4197.

Gray, A.L., R.K. Hawkins, C.E. Livingstone, L.D. Arsenault, and W.M. Johnstone, 1982: Simultaneous scatterometer and radiometer measurements of sea-ice microwave signatures. J. Oceanic Eng., 0E-7, 20-32.

Grenfell, T.C., 1984: Surface based brightness temperatures of sea ice in the Bering and Greenland seas. Proc. Int. Geosci. and Remote Sensing Symp., Strasbourg, France.

Grody, N.C., 1976: Remote sensing of atmospheric water content from satellites using microwave radiometry. IEEE Trans. A. and T., AP-24, 155162.

Hall, R.T., and D.A. Rothrock, 1981: Sea ice displacement from Seasat synthetic aperture radar. J. Geophys. Res., 86, 11078-11082.

Hibler, W.D., III, and S.F. Ackley, 1983: Numerical simulation of the Weddell Sea pack ice. J. Geophys. Res., 88., 2873-2887.

Hollinger, J.P., and R.C. Lo, 1983: SSM/I Project Summary Report. NRL Memo. Rep. 5055, Naval Research Laboratory, Washington, D.C., 106 pp.

Hollinger, J.P., B.E. Troy, R.O. Ramseier, K.W. Asmus, M.F. Hartman, and C.A. Luther, 1984: Microwave emission from high arctic sea ice during freeze-up. J. Geophys. Res., 89, 8104-8122.

Hunkins, 1983: personal communication.

Koerner, R.M., 1973: The mass balance of the sea ice of the Arctic Ocean, J. Glaciol., 12, 173-185.

Kukla, G., and J. Gavin, 1981: Summer ice and carbon dioxide. Science, 214, 497-503. 
Kunzi, K.F., S. Patil, and H. Rott, 1982: Snow cover parameters retrieved from NIMBUS 7 scanning multichannel microwave radiometer (SMMR) data. IEEE Trans. of Geoscience and Remote Sensing, GE-20, 452-467.

Martinson, D.G., P.D. Killworth, and A.L. Gordon, 1981: A convective model for the Weddell polynya. J. Phys. Oceanogr., 11, 466-488.

Maykut, G.A., and N. Untersteiner, 1971: Some results from a time dependent thermodynamic model of sea ice. J. Geophys. Res., 76, 1550-1576.

McNutt, L., 1981: Ice conditions in the eastern Bering Sea from NOAA and Landsat imagery: winter conditions 1974, 1976, 1977, 1979. NOAA TM ERL PMEL-24, Pacific Marine Environmental Laboratory, Seattle, 179 Pp.

MIZEX-West Study Group, 1983: MIZEX-West: Bering Sea Marginal Ice Zone Experiment. EOS, 64, 578-579.

NASA-JPL, 1983: Science Program for an Imaging Radar Receiving Station in Alaska: Report of the Science Working Group. Jet Propulsion Laboratory, Pasadena, 45 pp.

Njoku, E.G., 1982: Passive microwave remote sensing of the earth from space - a review. Proc. IEEE, 70, 728-750.

Parkinson, C.L., and D.J. Cavalieri, 1982: Interannual sea-ice variations and sea-ice/atmosphere interactions in the Southern Ocean, 1973-1975. Ann Glaciol., 3, 249-254.

Parkinson, C.L., 1983: On the development and cause of the Weddell polynya in a sea ice simulation. J. Phys. Oceanogr., 13, 501-511.

Pritchard, R.S. (Ed.), 1980: Sea Ice Processes and Models. University of Washington Press, Seattle, 474 Pp.

Rotman, S.R., A.D. Fisher, and D.H. Staelin, 1982: Inversion for physical characteristics of snow using passive radiometric observation. J. Glaciol., 28, 179-185.

Sarmiento, J.L., and J.R. Tottweiler, 1984: A new model for the role of the ocean in determining atmospheric $\mathrm{PCO}_{2}$. Nature, 308, 621-623.

Streten, N.A., 1973: Satellite observations of the summer decay of the Antarctic sea-ice. Arch Met. Geoph. Biokl., Ser. A, 22, 119-134.

Svendsen, E., K. Kloster, B. Farrelly, O.M. Johannessen, J.A. Johannessen, W.J. Campbell, P. Gloersen, D. Cavalieri, and C. Maetzler, 1983: Norwegian remote sensing experiment: evaluation of the Nimbus? scanning multichannel microwave radiometer for sea ice research. J. Geophys. Res., 88, 2781-2792.

Swift, C.T., L.S. Fedor, and R.0. Ramseier, 1984: An algorithm to measure sea ice concentration with microwave radiometers. J. Geophys. Res., in press. 
Troy, B.E., J.P. Hollinger, R.M. Lerner, and M.M. Wisler, 1981: Measurement of the microwave properties of sea ice at $90 \mathrm{GHz}$ and lower frequencies. J. Geophys. Res., 86, 4283-4289.

Untersteiner, N., 1968: Natural desalination and equilibrium salinity profile of perennial sea ice. J. Geophys. Res. 73, 1251-1257.

Untersteiner, N., 1984: The cryosphere. In: The Global Climate, J.T. Houghton, Ed., Cambridge Univ. Press, pp. 121-140.

Untersteiner, N., and A.S. Thorndike, 1982: Arctic data buoy program. Polar Record, 21, 127-135.

Wadhams, P., 1981: Sea ice topography of the Arctic Ocean in the region $70^{\circ} \mathrm{W}$ to $25^{\circ} \mathrm{E}$. Phil. Trans. Royal Soc. London, 302, 45-85.

Wadhams, P., and R.J. Horne, 1980: An analysis of ice profiles obtained by submarine sonar in the Beaufort Sea. J. Glaciol., 25, 401-424.

Walsh, J.E., and C.M. Johnson, 1979: An analysis of arctic sea ice fluctuations, 1953-1977. J. Phys. Oceanogr., 9, 580-591.

WMO-ICSU, 1981: Preliminary Plan for the World Climate Research Programme. WCP-2, World Meteorological Organization, Geneva.

WMO-ICSU, 1984: Report of the Meeting of Experts on Sea Ice and Climate Modelling (Geneva, December 1983). WCP-77, World Meteorological Organization, Geneva, pp. 1-34.

Zwally, H.J., 1977: Microwave emissivity and accumulation rate of polar firn. J. Glaciol., 18, 195-215.

Zwally, H.J., and P. Gloersen, 1977: Passive microwave images of the polar regions and research applications. Polar Record, 18, 431-450.

Zwally, H.J., J.C. Comiso, C.L. Parkinson, W.J. Campbell, F.D. Carsey, and P. Gloersen, 1983a: Antarctic Sea Ice, 1973-1976: Satellite PassiveMicrowave Observations. NASA SP-459. National Aeronautics and Space Administration, Washington, D.C., 206 pp.

Zwally, H.J., C.L. Parkinson, and J.C. Comiso, 1983b: Variability of Antarctic sea ice and $\mathrm{CO}_{2}$ change. Science, 220, 1005-1012. 


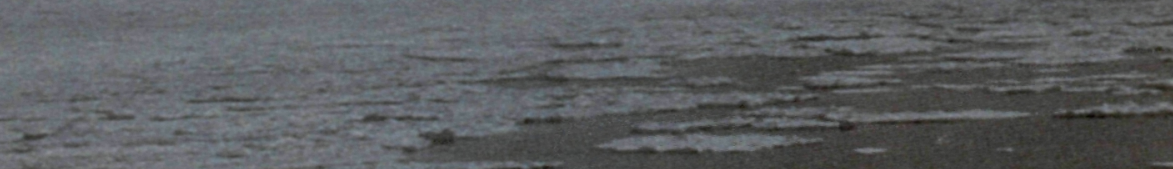
Lis.

$\frac{1}{2}+2 x-5 y+2=$

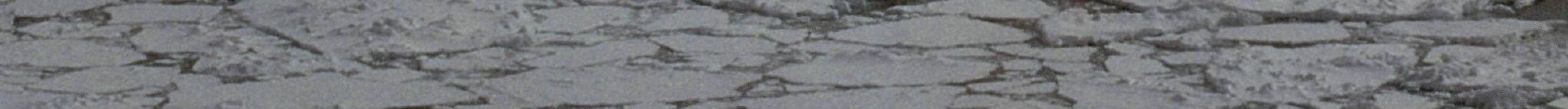

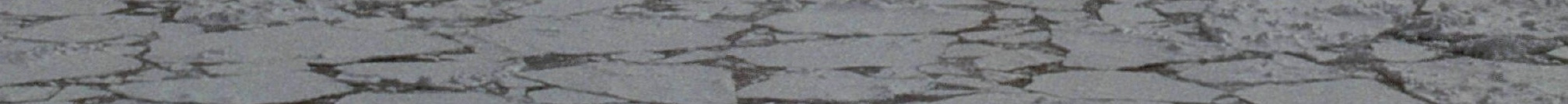
$5 ?->+15$ -12
2 and $x$ x 